\title{
Review
}

\section{Getting TRAIL back on track for cancer therapy}

\author{
J Lemke ${ }^{1,2}$, S von Karstedt ${ }^{1}$, J Zinngrebe ${ }^{1}$ and H Walczak ${ }^{\star 1}$
}

Unlike other members of the TNF superfamily, the TNF-related apoptosis-inducing ligand (TRAIL, also known as Apo2L) possesses the unique capacity to induce apoptosis selectively in cancer cells in vitro and in vivo. This exciting discovery provided the basis for the development of TRAIL-receptor agonists (TRAs), which have demonstrated robust anticancer activity in a number of preclinical studies. Subsequently initiated clinical trials testing TRAs demonstrated, on the one hand, broad tolerability but revealed, on the other, that therapeutic benefit was rather limited. Several factors that are likely to account for TRAs' sobering clinical performance have since been identified. First, because of initial concerns over potential hepatotoxicity, TRAs with relatively weak agonistic activity were selected to enter clinical trials. Second, although TRAIL can induce apoptosis in several cancer cell lines, it has now emerged that many others, and importantly, most primary cancer cells are resistant to TRAIL monotherapy. Third, so far patients enrolled in TRA-employing clinical trials were not selected for likelihood of benefitting from a TRA-comprising therapy on the basis of a valid(ated) biomarker. This review summarizes and discusses the results achieved so far in TRA-employing clinical trials in the light of these three shortcomings. By integrating recent insight on apoptotic and non-apoptotic TRAIL signaling in cancer cells, we propose approaches to introduce novel, revised TRAIL-based therapeutic concepts into the cancer clinic. These include (i) the use of recently developed highly active TRAs, (ii) the addition of efficient, but cancer-cell-selective TRAIL-sensitizing agents to overcome TRAIL resistance and (iii) employing proteomic profiling to uncover resistance mechanisms. We envisage that this shall enable the design of effective TRA-comprising therapeutic concepts for individual cancer patients in the future.

Cell Death and Differentiation (2014) 21, 1350-1364; doi:10.1038/cdd.2014.81; published online 20 June 2014

Facts

- The discovery that TRAIL can induce apoptosis selectively in cancer cells has initiated the development of TRAs for clinical application.

- First results of TRA-employing clinical trials revealed that TRAs are well tolerated but failed to show robust therapeutic activity in patients.

- In recent years, it has emerged that, although TRAIL can induce apoptosis in many cancer cell lines, many other cell lines and most primary cancers are TRAIL resistant. Noteworthy, in some TRAIL-resistant cancer cells TRAIL can trigger non-apoptotic signaling pathways, which can contribute to their malignancy.

- Several means to overcome TRAIL resistance of cancer cells have been reported, including combination of TRAs with chemo- or radiotherapy or with targeted small molecules such as Smac mimetics, BH3 mimetics or inhibitors of kinases or the proteasome.

\section{Open Questions}

- Why could the promising preclinical results obtained with TRAs not be successfully translated into anticancer activity in patients?

- What are novel TRAs with improved pharmacokinetic properties which could be taken forward into clinical application without causing toxicity?

- Which TRAIL-apoptosis sensitizing strategies should be considered for novel therapeutic combinations to overcome TRAIL resistance?

- How can reliable molecular markers be identified to select cancer patients that are likely to benefit from particular TRA-comprising therapies?

Most current therapeutic strategies to treat cancer patients aim to overcome two key hallmarks of cancer, i.e., excessive proliferation and apoptosis resistance. ${ }^{1}$ In contrast to inhibiting proliferation, which will mostly achieve stable disease by limiting

${ }^{1}$ Centre for Cell Death, Cancer and Inflammation (CCCI), UCL Cancer Institute, University College London, 72 Huntley Street, London WC1E 6DD, UK and ${ }^{2}$ Clinic of General and Visceral Surgery, University of Ulm, Albert-Einstein-Allee 23, 89081 Ulm, Germany

${ }^{*}$ Corresponding author: H Walczak, Centre for Cell Death, Cancer and Inflammation (CCCI), UCL Cancer Institute, University College London (UCL), 72 Huntley Street, London WC1E 6DD, UK. Tel: + 44207679 46471; Fax: + 44207679 6925; E-mail: h.walczak@ucl.ac.uk

Abbreviations: CDK, Cyclin-dependent kinase; cFLIP, cellular FLICE-like inhibitory protein; cIAP, cellular IAP; DD, death domain; DED, death effector domain; DR, death receptor; DISC, death-inducing signaling complex; FADD, Fas-associated protein with death domain; IAP, Inhibitor of apoptosis protein; iz, isoleucine zipper; LZ, leucine zipper; MOMP, mitochondrial outer membrane permeabilization; OPG, osteoprotegerin; RCT, randomized controlled trial; Smac, second mitochondrial activator of caspases; TNF, tumor necrosis factor; TRAF2, TNF-receptor associated factor 2; TRAIL, tumor necrosis factor-related apoptosis-inducing ligand; TRAIL-R, TRAIL-receptor; TRA, TRAIL-R agonist; XIAP, X-linked inhibitor of apoptosis protein

Received 17.2.14; revised 14.4.14; accepted 15.4.14; Edited by G Melino; published online 20.6.14 
tumor outgrowth, induction of apoptosis bears the potential to eliminate cancer cells, which could provide an opportunity for cure.

Apoptosis can be induced via an intrinsic and an extrinsic pathway. The intrinsic apoptosis pathway senses cellular damage, including misbalanced intracellular homeostasis, oxidative stress and DNA damage, thereby triggering the cell death program to eliminate non-functional cells and to maintain tissue integrity. ${ }^{2}$ As this pathway depends on mitochondria, it is also referred to as the 'mitochondrial' apoptosis pathway. ${ }^{3}$ A central molecule in detecting cellular damage and triggering intrinsic apoptosis is the tumor-suppressor protein p53. Importantly, most conventional radio- and chemotherapies induce DNA damage that activates the intrinsic apoptotic pathway in a p53-dependent manner. ${ }^{4}$ However, functional inactivation of $p 53$, either by mutation or loss of expression, is one of the most common genetic events in cancer. Hence, most cancer cells are either primarily resistant or acquire resistance to these conventional therapies. $^{5}$

The extrinsic apoptosis pathways are triggered by binding of death ligands to transmembrane receptors, so-called death receptors (DRs), thereby transmitting a death signal coming from the outside of the cell. Importantly, even though p53 has been shown to be capable of influencing DR-induced apoptosis signaling in certain cancers, mainly by influencing DR expression itself, ${ }^{6,7}$ in most cases p53 appears to be dispensable for apoptosis induction by DRs. ${ }^{8}$ Hence, stimulation of the extrinsic apoptosis pathway is bound to be more effective than chemotherapy for treating cancers with TP53 mutations.

Discovered in 1975, the first death ligand considered for anticancer therapy was tumor necrosis factor (TNF). ${ }^{9}$ However, although TNF induced cell death in some cancer cells, it soon became evident that TNF's primary function is the production of pro-inflammatory factors and that this activity is causative for the severe toxicity induced by systemic application of this cytokine. ${ }^{10-12}$ Subsequently, two agonistic antibodies targeting the newly identified DR FAS/APO-1 (CD95) were shown to be capable of inducing apoptosis in a wide range of cancer cells. ${ }^{13-16}$ Again, initial optimism to target CD95 for anticancer therapy was stunted by the fact that systemic treatment with recombinant CD95L or CD95agonistic antibodies resulted in fulminant and lethal hepatotoxicity. ${ }^{17} \mathrm{~A}$ few years later, TNF-related apoptosis-inducing ligand (TRAIL/Apo2L) was identified based on its sequence homology to TNF and CD95L. ${ }^{18,19}$ Similar to TNF and CD95L, TRAIL induced apoptosis in cancer cells. Importantly, however, and in contrast to TNF and CD95L, systemic treatment with TRAIL in vivo killed tumor cells without causing toxicity. ${ }^{20,21}$ Thereby, a death ligand with the promising feature of cancer selectivity had been discovered. Apart from sparking the development of TRAIL-receptor (TRAIL-R) agonists (TRAs) for clinical application as potential novel cancer therapeutics, this discovery resulted in intense worldwide research efforts to unravel the signal transduction machinery triggered by this ligand, especially concerning apoptosis induction in cancer cells and how resistance to TRAIL-induced apoptosis may be overcome when it is encountered.

\section{TRAIL-Induced Apoptosis}

Two TRAIL-Rs are capable of transmitting apoptosis, i.e., TRAIL-R1 (also known as DR4) ${ }^{22}$ and TRAIL-R2 (also known as Apo2, KILLER, DR5 or TRICK2; Figure 1). ${ }^{7,23-26}$ Binding of TRAIL, which naturally occurs as a trimer, to TRAIL-R1 and/or TRAIL-R2 induces receptor trimerization, the prerequisite for formation of the death-inducing signaling complex (DISC). The adaptor protein Fas-associated protein with death domain (FADD) is recruited to the death domain (DD) of these TRAIL-Rs via its own DD. FADD in turn recruits procaspase-8/10 to the DISC via homotypic death effector domain (DED) interaction as both FADD and these caspases contain DEDs capable of interacting with each other. ${ }^{27-30}$ Both caspase- 8 and caspase-10 are recruited to and activated at the DISC. Whereas caspase-8 is the apoptosisinitiating caspase at the DISC, caspase-10 is not required for apoptosis induction and indeed cannot substitute for caspase-8 as pro-apoptotic caspase at the DISC. ${ }^{29}$ Caspase- 8 is recruited as an enzymatically inactive pro-caspase. It is activated by a proximity-induced conformational change at the DISC and subsequently fully activated by auto-catalytic cleavage and formation of homodimers (reviewed in Kantari and Walczak ${ }^{31}$ ). Upon release of active homodimers from the DISC, caspase-8 cleaves and activates downstream substrates of the apoptotic pathway (summarized in Figure 2). Recent work using quantitative mass spectrometry has shed light on the stoichiometry of the TRAIL-DISC, by demonstrating that three TRAIL-R1/2 receptors recruit only one FADD molecule, which subsequently recruits multiple pro-caspase-8 molecules. $^{32}$ Based on the presence of two DEDs in caspase- 8 , the authors propose a model in which the first pro-caspase-8 protein is recruited to the DISC via interaction with the DED of FADD, whereas additional pro-caspase-8 molecules are recruited to the first one by interaction via their respective DEDs resulting in chain formation of pro-caspase-8 molecules. Intriguingly, a very similar model of DISC stoichiometry was also reported for the CD95-system. ${ }^{33}$

In addition to TRAIL-R1 and TRAIL-R2, TRAIL can also bind to two non-DD-containing membrane-bound receptors, TRAIL-R3 (also known as decoy receptor 1 (DcR1)) 23,25,34-36 and TRAIL-R4 (DcR2) ${ }^{37-39}$ (Figure 1). Although the extracellular domains of these receptors are highly homologous to those of TRAIL-R1/2, TRAIL-R3 is a glycosyl-phosphatidyl-inositol-anchored receptor lacking an intracellular domain and TRAIL-R4 only contains a truncated, non-functional DD in its intracellular domain. Consequently, these two receptors are incapable of inducing apoptosis. As TRAIL-R3/4 can nevertheless bind TRAIL, they might compete with the apoptosis-inducing DD-containing TRAILRs for ligand binding, which led to the hypothesis that these receptors may act as decoys for TRAIL. Indeed, they were both shown to be capable of inhibiting TRAIL-induced apoptosis when overexpressed. ${ }^{40,41}$ In addition to a possible TRAIL-sequestering function, TRAIL-R4 might impair TRAILinduced apoptosis by forming inactive hetero-complexes with TRAIL-R2, ${ }^{40,42}$ and/or by triggering anti-apoptotic signaling pathways such as NF- $\kappa$ B and PKB/AKT. ${ }^{37,43}$ Nevertheless, as all of the above-mentioned mechanisms have almost exclusively been studied in overexpression systems, the 


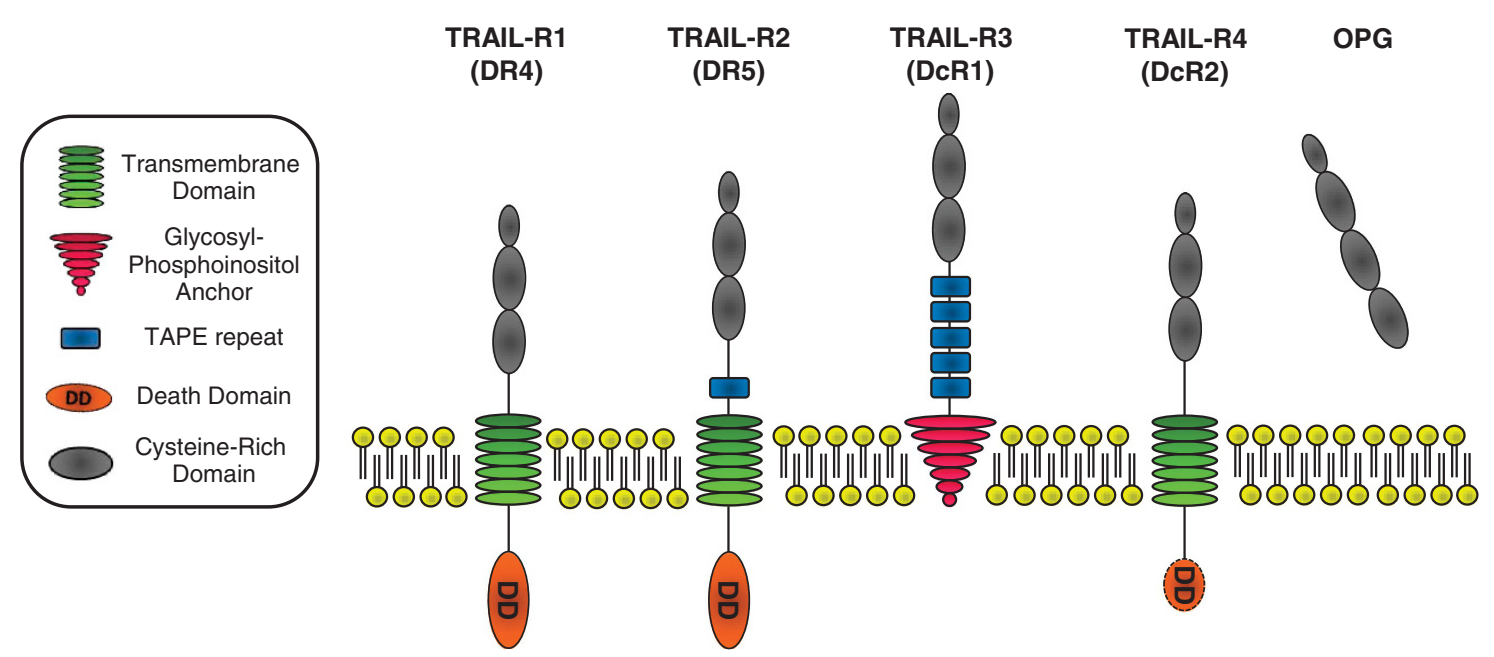

Figure 1 Overview of the TRAIL-R system in humans. TRAIL can bind to four membrane-bound and to one soluble receptor. TRAIL-R1 (DR4) and TRAIL-R2 (DR5) can induce apoptosis via their DDs. In contrast, TRAIL-R3 (DcR1), TRAIL-R4 (DcR2) and the soluble receptor osteoprotegerin (OPG) have been suggested to impair TRAILinduced apoptosis as they are capable of binding to TRAIL but lack a functional DD required for apoptosis induction. TRAIL-R3 is as glycosyl-phosphatidyl-inositol-anchored protein that completely lacks an intracellular domain. TRAIL-R4 is inserted in the membrane via a transmembrane domain but only expresses a truncated death domain, which is incapable of inducing apoptosis

physiological function of endogenously expressed TRAIL-R3/4 and whether they can indeed interfere with TRAIL-induced apoptosis under physiological expression conditions remains to be established. Clinically, this understanding will be of great interest given that TRAIL-R3 is highly expressed in many primary gastrointestinal cancers ${ }^{44}$ and that high TRAIL-R4 expression is associated with poor prognosis in breast cancer. ${ }^{45}$

In addition to the four membrane-bound TRAIL-Rs, the soluble TNF receptor superfamily member Osteoprotegerin (OPG), mainly involved in regulating osteoclast activity by inhibiting RANKL, ${ }^{46}$ has also been reported to interact with TRAIL $^{47}$ (Figure 1). Whereas exogenous application of recombinant OPG has indeed been shown to be capable of inhibiting TRAIL-induced apoptosis, ${ }^{48,49}$ the apparently rather low affinity between TRAIL and OPG at physiological temperatures casts doubt on the physiological relevance of this interaction and, hence, of endogenously expressed OPG in impairing TRAIL signaling. ${ }^{50}$ This notion is further supported by the intriguing observation that no in vivo study in which high-dose TRAIL treatments have been employed over extended periods of time has reported any bone anomalies. This would, however, be expected in such animals if the TRAIL-OPG interaction were of physiological relevance. In summary, TRAIL is the most promiscuous TNF family member as it binds to at least four different receptors.

The physiological reason for having such a variety of TRAIL-Rs in humans is still not fully understood. Intriguingly, in mice only one death-inducing receptor is expressed, mTRAIL-R (MK/mDR5), which shares $43 \%$ and $49 \%$ sequence homology with human TRAIL-R1 and TRAIL-R2, respectively. ${ }^{51}$ In addition to mTRAIL-R, mice express two potential decoy receptors, mDcTRAIL-R1 and mDcTRAIL-R2, which are, however, quite distinct from the human decoy receptors, TRAIL-R3 and $-4 .{ }^{52}$ These differences between mice and men suggest that the presence of two TRAIL-R genes with a full DD in humans might have been a rather recent evolutionary event, and it is still not entirely clear as to why humans have two DD-containing TRAIL-Rs.

The emerging role of the ubiquitin-system in controlling DISC activity. Recent evidence suggests post-translational modification by ubiquitination to be a crucial regulator of DISC activity. The E3 ligase Cullin3 has been reported to be recruited to the DISC where it was shown to poly-ubiquitinate caspase-8, leading to DISC recruitment of the ubiquitinbinding protein $\mathrm{p62}$, which stabilizes activated caspase-8, thereby facilitating DISC activation. ${ }^{53}$ Second, it has been shown that TNF receptor-associated factor 2 (TRAF2) is recruited to the DISC where it mediates attachment of K48linked ubiquitin chains to caspase-8. This targets caspase-8 for proteasomal degradation and, hence, limits DISC activity. ${ }^{54}$ Whether or not this K48-linked ubiquitination is directly mediated by TRAF2 is currently debated as structural and functional studies by others concluded that TRAF2 may not be able to act as an E3 ligase on its own. ${ }^{55,56}$ In summary, the DISC is a highly dynamic protein complex that requires tight regulation. This regulation is, at least in part, achieved by ubiquitination (Figure 2).

Type-I versus type-ll cells. Cells have been classified in two categories based on the pathway which they employ for apoptosis induction upon DISC activation, a phenomenon which was first described for the CD95/CD95L system. ${ }^{57}$ In so-called type-I cells, DISC activation is strong and stable enough to induce robust caspase-8 activation, which is, in turn, sufficient to directly and fully activate the effector caspase-3, resulting in apoptosis. In type-II cells, DISCinduced caspase- 3 activation is incomplete and insufficient to induce apoptosis. Therefore, additional triggering of the mitochondrial pathway is required to induce apoptosis in these cells. To achieve triggering of the mitochondrial pathway, caspase-8 cleaves the pro-apoptotic $\mathrm{BH} 3-$ only protein Bid, generating truncated Bid. ${ }^{58}$ Truncated Bid in 


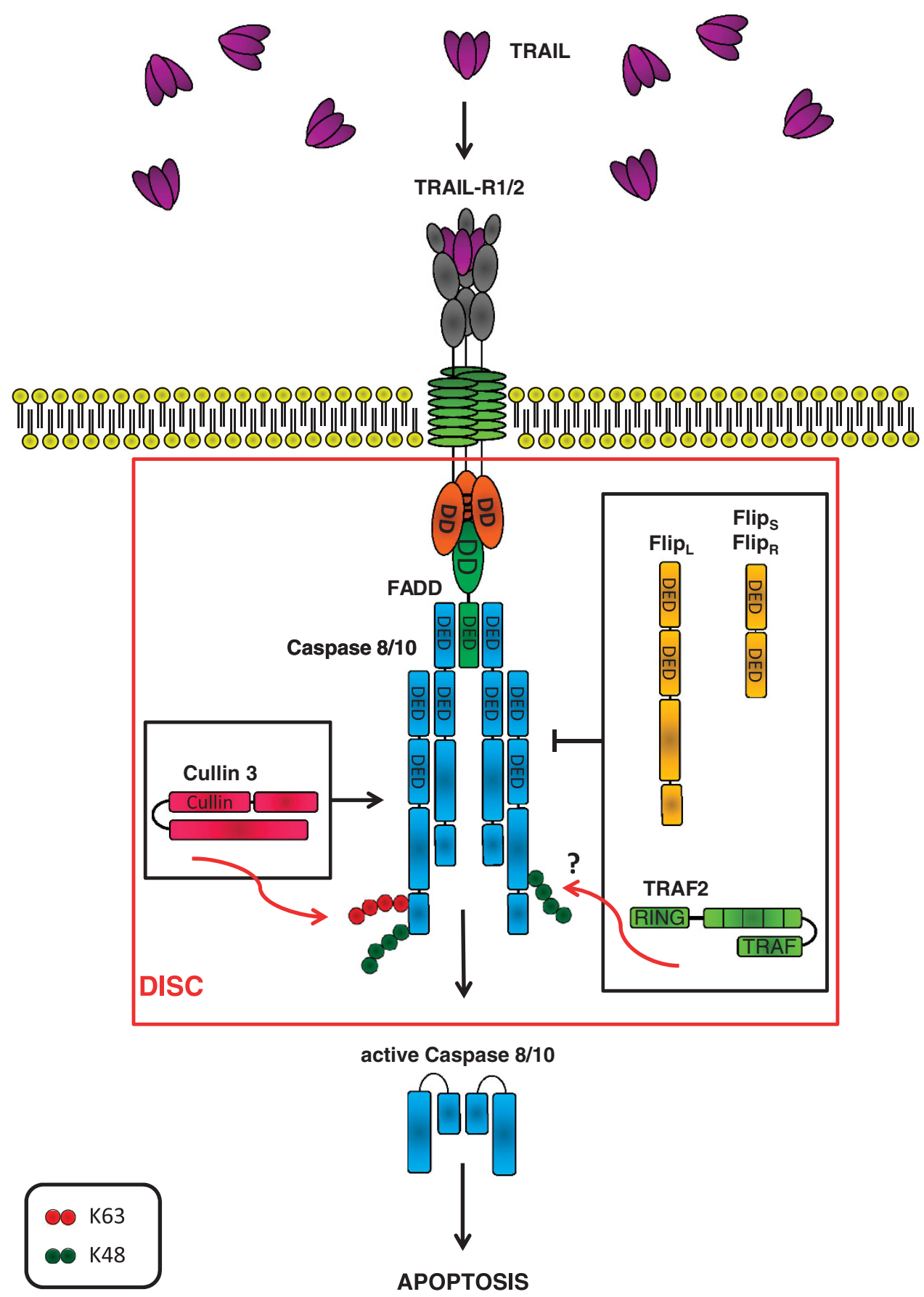

Figure 2 The current model of TRAIL-induced DISC formation. Upon binding of trimerized TRAIL to TRAIL-R1/2, the adaptor molecule FADD is recruited via homotypic DD interaction. Subsequently, FADD recruits pro-caspase-8/10 molecules via their respective DEDs. These pro-caspases are cleaved and activated at the DISC, initiating the apoptosis signaling cascade. The E3 ligase Cullin3 has been shown to stabilize DISC formation by polyubiquitination of caspase-8. Different forms of cFLIP can inhibit DISC formation by competing with caspase-8/10 for binding to FADD. TRAF2 has been suggested to negatively regulate DISC activity by promoting K48-linked ubiquitination and subsequent proteasomal degradation of caspase-8

turn activates the pro-apoptotic Bcl-2-family members Bax and Bak enabling them to permeabilize the mitochondrial outer membrane (reviewed in Westphal et $a l^{59}$ ). Upon mitochondrial outer membrane permeabilization (MOMP), pro-apoptotic factors such as cytochrome- $c$ are released. Cytoplasmic cytochrome- $c$ associates with Apaf-1 and procaspase- 9 to form the multiprotein complex known as the apoptosome, an activation platform for pro-caspase-9 that initiates effector caspase cleavage ultimately leading to apoptosis (Figure 3).

Initially, differential efficiency in forming an active DISC was thought to be the decisive factor distinguishing type-I from type-II cells. ${ }^{60}$ However, more recently it was demonstrated that the anti-apoptotic factor $\mathrm{X}$-linked inhibitor of apoptosis 


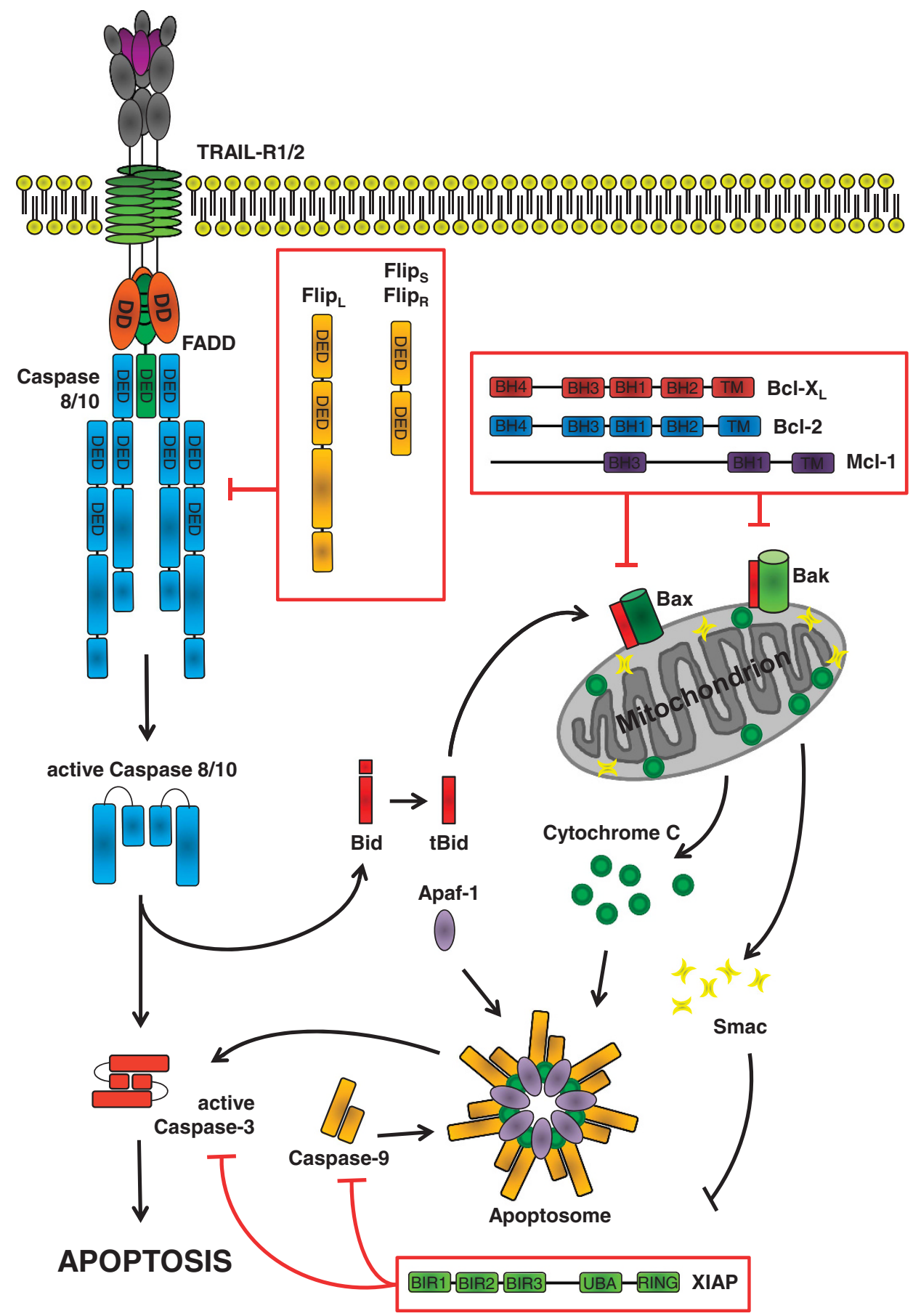

Figure 3 TRAIL-induced apoptosis. In type-I cells, DISC-activated caspase-8 is sufficient to directly cleave and activate the downstream effector caspase-3. In type-II cells, activation of the mitochondrial apoptosis pathway, mediated by caspase-8-dependent cleavage of Bid, is required to achieve effector caspase activation. Truncated Bid (tBid) translocates to the mitochondria where it induces Bax/Bak-mediated mitochondrial outer membrane permeabilization (MOMP). MOMP releases pro-apoptotic factors such as cytochrome-c and Smac/DIABLO into the cytosol. Cytosolic cytochrome-c aggregates with Apaf-1 and procaspase-9 to form the apoptosome, the activation platform for caspase-9. Active caspase-9 cleaves, and thereby activates, downstream effector caspases including caspase-3. The TRAIL-induced apoptosis cascade is inhibited at various levels: (i) at the DISC, cFLIP competes with caspase-8 for binding to FADD; (ii) at the mitochondria, anti-apoptotic $\mathrm{Bcl}-2$ family members like $\mathrm{Bcl}-2$, Bcl-xL and $\mathrm{Mcl}-1$ inhibit pro-apoptotic Bax- and Bak-mediated MOMP and (iii) at the level of effector caspases, XIAP inhibits them by direct interaction. Hence, together with the extent of DISCgenerated caspase-8 activity, the ratio of the expression of caspase-3 to XIAP is crucial for categorization of a particular cell line as type-I or type-II

proteins (XIAPs) is a crucial factor in making this distinction. ${ }^{61}$ XIAP counteracts apoptosis induction by directly inhibiting caspase- $3,{ }^{62}$ and in type-II cells a high XIAP/caspase-3 ratio prevents full caspase-3 activation by caspase-8.
In summary, it appears that the DISC's capacity to cleave caspase- 3 and the ratio of XIAP to caspase- 3 in a given cell are together critical for the distinction between type-I and type-II cells. 


\section{TRAIL-Induced Necroptosis}

Recently, it was demonstrated that DR triggering may also program cells to die in a caspase-independent, necrotic way (known as programmed necrosis or necroptosis). ${ }^{63}$ Necroptosis depends on the formation of a complex containing the kinases RIP1 and RIP3. This complex, also called necrosome, mainly forms in scenarios when caspase-8 is absent or when its activity is blocked. The necrosome in turn recruits and phosphorylates the pseudokinase MLKL, which was shown to be required for necroptosis induction. ${ }^{64,65}$ How MLKL ultimately leads to necroptosis induction is still not fully understood, but recent studies suggest that MLKL might be recruited to the plasma membrane where it forms pores leading to membrane permeabilization. ${ }^{66,67}$ Intriguingly, not only TNF but also CD95L and TRAIL were shown to be capable of inducing necroptosis. ${ }^{68-71}$ Given the emerging role of necroptosis in pathophysiological processes and the resulting therapeutic potential of targeting necroptosis, this discovery may turn out to become important.

\section{Resistance Mechanisms to TRAIL-Induced Apoptosis}

Cellular FLICE-like inhibitory protein (cFLIP): regulator of caspase-8 activation at the DISC. To avoid excessive apoptosis induction by TRAIL, several mechanisms to countervail TRAIL-induced apoptosis have evolved in normal cells and are frequently exacerbated in tumor cells to escape TRAIL-induced apoptosis. Formation of the DISC is controlled by cFLIP (Figure 2). Three splice variants, cFLIP-long $\left(c F L I P_{L}\right)$, cFLIP-short (cFLIP $)_{S}$ and cFLIP-Raji $\left(c F L I P_{R}\right)$, are expressed on the protein level. ${ }^{72,73}$ All three of these cFLIP variants contain two $\mathrm{N}$-terminal DEDs that are highly homologous to the two DEDs of caspases-8 and -10. cFLIPS and $\mathrm{CFLIP}_{\mathrm{R}}$ are analogous as they both contain a short C-terminal domain, albeit slightly different ones. In contrast, $\mathrm{CFLIP}_{\mathrm{L}}$ contains a long C-terminal domain, which closely resembles the caspase portion of caspase- 8 but lacks catalytic activity. Both CFLIP $_{S}$ and CFLIP $_{R}$ compete with caspase-8 and casapse-10 for binding to FADD thereby inhibiting the pro-apoptotic activity of the DISC. ${ }^{72,73}$ In contrast, the role of $C F L I P_{L}$ in regulating apoptosis appears to be more complex and seems to depend on expression levels and the intensity of receptor stimulation (reviewed in Ozturk et $a l^{4}$ ). cFLIP acts similar to the short cFLIP variants in an anti-apoptotic manner when expressed at high levels. When expressed at lower levels, however, cFLIP $\mathrm{L}_{\mathrm{L}}$ can also facilitate apoptosis by enhancing pro-caspase-8 recruitment to the DISC. ${ }^{75,76}$ Interestingly, cFLIP splice variants have also been shown to differentially control necroptosis induction. By completely preventing caspase- 8 activation at the DISC, cFLIPS can promote RIP-1/-3-dependent necroptosis induction. By contrast, CFLIP $\mathrm{P}_{\mathrm{L}}$ is thought to inhibit necroptosis in concert with caspase-8 because of formation of $C F L I P_{L} /$ caspase- 8 heterodimers resulting in localized caspase-8 activity and consequent inactivation of RIP1 and RIP3. ${ }^{71,77,78}$ In summary, cFLIP is a crucial regulator of the DISC and can inhibit, promote or switch the signaling output of DR stimulation. Therefore, cFLIP is an attractive target when exploiting DR-induced cell death for cancer therapy.
The Bcl-2 family: balancing death and survival at the mitochondrion. MOMP, the hallmark of the intrinsic apoptosis pathway, is positively and negatively regulated by three different classes of Bcl-2 family members: (i) pro-apoptotic effectors (Bax, Bak and possibly Bok), (ii) pro-survival factors (e.g., Bcl-2, Bcl-xL and $\mathrm{Mcl}-1$ ) and (iii) pro-apoptotic inducers, which are BH3-only proteins (e.g., Bid, Bim, Puma, Noxa; reviewed in Shamas-Din et $a l^{79}$ ). The latter proteins are sensors for apoptotic stimuli and activated by transcriptional induction, posttranslational modification or, in case of Bid, by caspase-8-mediated proteolysis. ${ }^{80}$ Bax and Bak, the executioners of the mitochondrial apoptosis pathway, are kept in check by anti-apoptotic factors such as BcL-2, Bcl-xL and Mcl-1. Thus, the balance of pro- versus anti-apoptotic $\mathrm{Bcl}-2$ family members tightly regulates MOMP and, thereby, the mitochondrial apoptosis pathway. Alterations in this balance, e.g., by overexpression of anti-apoptotic Bcl-2 family members or loss of expression of pro-apoptotic members, frequently occur in cancers with the consequence that these cancers are rendered resistant to conventional chemo- and radiotherapy (reviewed in Indran et $a^{81}$ ). With respect to TRAIL signaling, it has been shown that type-II cancer cells can acquire resistance to TRAIL-induced apoptosis by loss of $\mathrm{Bax}^{82}$ or increased expression of $\mathrm{Bcl}-2,{ }^{83} \mathrm{Bcl}-\mathrm{xL}^{84}$ or $\mathrm{Mcl}-1^{85}$ (Figure 3).

Inhibitor of apoptosis proteins (IAPs): caspase inhibitors with emerging roles in the ubiquitin system. The family of IAPs comprises of a number of members of which XIAP, cellular IAP (CIAP)1 and clAP2 have been most extensively studied. All IAPs are characterized by containing at least one baculovirus IAP repeat (BIR) domain. Their anti-apoptotic function has been known for a long time and has initially been solely attributed to their ability to directly inhibit caspases. Indeed, XIAP was shown to prevent activation of caspases-3, -7 and -9 via direct binding mediated by its BIR domains. ${ }^{62}$ As outlined above, its prominent role in regulating apoptosis is also highlighted by its critical function in distinguishing between type-I and type-II apoptosis signaling. In addition to cytochrome- $c$, MOMP also results in release of the second mitochondrial activator of caspases (Smac/DIABLO) ${ }^{86}$ from the mitochondrial intermembrane space into the cytosol. Cytosolic Smac directly binds to XIAP, thereby blocking its inhibitory function on effector caspases and, in turn, allowing for their full activation. Initially, the anti-apoptotic role of cIAP1 and clAP2 was, similar to XIAP, mainly attributed to their direct inhibitory capacity toward caspases. Recently, however, it has emerged that, although clAP1 and clAP2 bind caspases, they cannot efficiently inhibit them. ${ }^{87}$ These results suggest that they exert their anti-apoptotic functions by other mechanisms than directly inhibiting caspases. Indeed, it has been demonstrated that clAP1 and clAP2, and also XIAP, possess E3-ligase activity via their Really Interesting New Gene (RING) domain, enabling them to ubiquitinate proteins. ${ }^{88-90}$ Besides auto-ubiquitination and degradation of clAPs, several ubiquitination targets of clAPs have been proposed, including caspase-3 and -7, targeting them for proteasomal degradation and thereby suppressing apoptosis. ${ }^{91}$ Furthermore, IAPs have been shown to also contribute to cell survival and apoptosis resistance in a caspase-independent 
manner by regulating a number of signaling pathways, most importantly NF- $\kappa$ B signaling, by ubiquitination events (reviewed in Gyrd-Hansen and Meier ${ }^{92}$ and Silke and Meier ${ }^{93}$ ). In summary, IAPs are critical regulators of TRAIL-induced apoptosis by either directly inhibiting caspases, targeting caspases for proteasomal degradation and/or by regulating cell survival signaling pathways such as $\mathrm{NF}-\kappa \mathrm{B}$.

\section{Non-Cell Death Signaling Pathways Induced by TRAIL}

In addition to apoptotic and in some cases necroptotic cell death, TRAIL treatment has been shown to induce a variety of non-cell death signaling pathways, including the NF- $\kappa \mathrm{B}$, MAPK, Src and phosphoinositide 3-kinase pathways (reviewed in Azijli et $a^{\rho^{4}}$ ). In line with the fact that activation of these pathways is known to promote malignancy of cancer cells, it could be demonstrated that TRAIL stimulation can enhance migration and invasion by activation of these pathways. ${ }^{95,96}$ Moreover, in vivo TRAIL treatment led to enhanced metastasis in an orthotopic xenograft model of pancreatic cancer ${ }^{96}$ and TRAIL-R2 expression in the same model might promote tumor cell proliferation by suppressing maturation of the microRNA let-7. ${ }^{97}$ One interesting study has revealed that KRAS-mutated colorectal cancer cell lines are not only more resistant to TRAIL-induced apoptosis induction than KRAS wild-type cells, but instead are stimulated to migrate when treated with TRAIL. ${ }^{98}$ In summary, these findings highlight that treating certain TRAIL-resistant cancers with TRAs might even bear the unwanted risk of worsening disease burden. It is, therefore, imperative to understand nonapoptotic signaling in order to preempt it. Interestingly, many cancers highly express TRAIL-R1 and TRAIL-R2 and their expression is not commonly lost during cancer progression, suggesting that their endogenous expression might provide an, as of yet, unknown advantage for disease progression of certain cancers also during later stages. It will therefore be interesting to investigate the function of the endogenous TRAIL/TRAIL-R system in cancers that are resistant to its apoptotic signaling output in order to understand the full implication of high TRAIL-R expression in cancer biology.

\section{Clinical Testing of TRAs}

Initial optimism to utilize DRs for anticancer therapy was dampened by the fact that systemic application of TNF and CD95L provoked severe toxicity. Paradoxically, more than 20 years later, targeting the TNF/TNF-R and CD95/CD95L system has become attractive for cancer therapy again, however, with the opposing pharmacological concept, as blockade of TNF or appears to exert therapeutic benefit in certain malignancies. ${ }^{99,100}$ In contrast, targeting of the TRAIL/ TRAIL-R system has so far focused on inducing a death signal in tumor cells and different TRAs have been developed and already undergone first clinical testing (Figure 4).

How to therapeutically target TRAIL-Rs: recombinant TRAIL versus agonistic TRAIL-R-specific antibodies. Current clinically tested TRAs comprise two categories of pharmacological agents: recombinant forms of TRAIL and agonistic antibodies specific for TRAIL-R1 or TRAIL-R2.
Targeting both, TRAIL-R1 and TRAIL-R2, using recombinant TRAIL might be advantageous because triggering both death-inducing TRAIL-Rs at the same time might result in a stronger death signal than an agonistic antibody specific for only one receptor. However, TRAIL might also bind nondeath-inducing TRAIL-Rs, which could hamper its apoptotic activity. Therefore, TRAIL-R1- or TRAIL-R2-specific TRAs such as antibodies would be more advised in the latter case. In this context, it is also interesting to note that for different cancer entities different contributions of TRAIL-R1 or TRAIL-R2 in transmitting TRAIL-induced signaling have been reported. Although colon and breast cancer cells primarily use TRAIL-R2 for apoptosis induction, ${ }^{101}$ lymphoid malignancies and pancreatic cancer cell lines have been reported to induce apoptosis primarily via TRAIL-R1. ${ }^{102-104}$ These differences in using one or the other receptor for apoptosis induction should be considered, when targeting cancer cells with TRAs specific for one of the two DD-containing TRAIL-R. In addition to these considerations, recombinant TRAIL and agonistic antibodies differ markedly in their pharmacokinetic properties. Whereas recombinant forms of human TRAIL are cleared within hours of systemic application, the half-life of therapeutic antibodies is typically in the range of several days to weeks. The higher half-life of antibodies hence circumvents the need for repeated or continuous application and allows a more stable concentration within cancerous tissues during treatment.

Surprisingly, it was recently shown that TRAIL treatment results in an antitumor effect in a mouse model in which tumor cells lack TRAIL-R expression suggesting that, at least in certain cases, TRAIL is also capable of exerting a therapeutic effect by targeting non-cancer cells, most likely cells in the tumor microenvironment. In the reported case, it was suggested that TRAIL-induced apoptosis in endothelial cells led to vascular disruption and tumor hemorrhage. ${ }^{105}$ This observation provides a novel approach to induce an antitumor effect by selectively targeting tumor vascularization. It should be noted, however, that tumor hemorrhage is a dreaded and potentially life-threatening event in cancer therapy and therefore patients should be carefully monitored for this potentially serious adverse effect during application of TRAs.

Safety and anticancer activity of TRAs in clinical trials. Dulanermin, so far the only form of recombinant TRAIL developed for clinical application, comprises the TNF homology domain within the extracellular domain of human soluble TRAIL (amino acids 114-281). ${ }^{20}$ In a number of phase-I clinical trials, dulanermin was found to be safe and well tolerated even when combined with chemotherapy or the CD20-targeting antibody rituximab (Figure 4 and Table 1). Moreover, these studies revealed some antitumor activity evidenced by partial or complete clinical response in a subset of patients. However, to evaluate specific anticancer activity of novel therapeutic interventions randomized controlled trials (RCTs) are required in which patients are assigned into treatment groups to receive standard-of-care therapy alone or combined with (a) novel pharmacological compound(s). So far, dulanermin was evaluated in two RCTs: one in non-small-cell lung cancer comparing dulanermin/ chemotherapy to chemotherapy alone ${ }^{106}$ and another in 


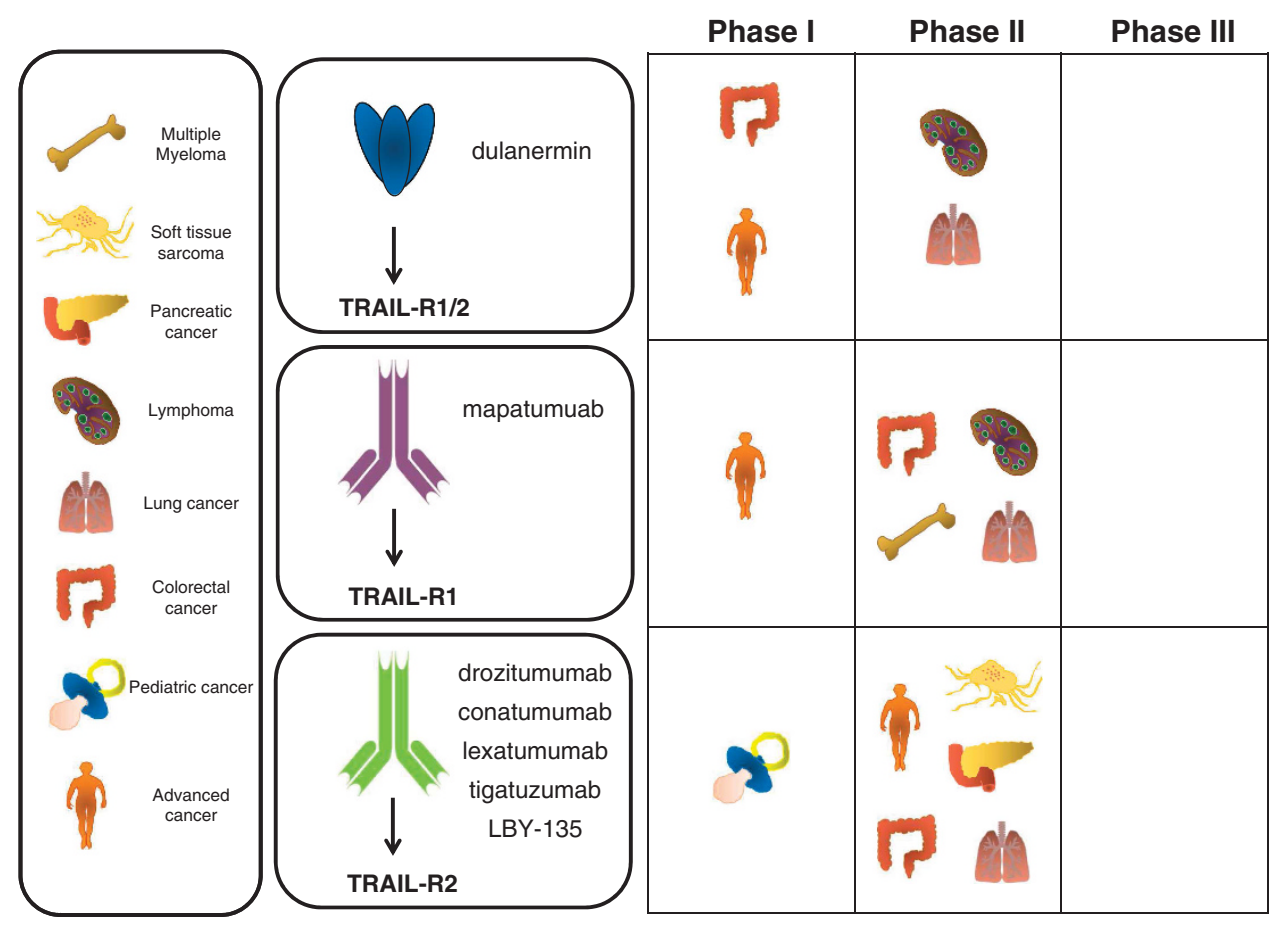

Figure 4 Progress of TRA in clinical trials. Schematic representation of the different TRA for which results of clinical trials have been reported. Cancer entities in which the different TRAs have been tested and the respective phase of clinical testing are shown

Table 1 Results of dulanermin (recombinant, soluble TRAIL) in clinical trials

\begin{tabular}{|c|c|c|c|c|c|c|}
\hline \multicolumn{7}{|c|}{ Dulanermin (AMG-951/rhApo2L) } \\
\hline Phase & $n$ & Cancer & Combination & Safety & Efficacy & Reference \\
\hline I & 71 & Advanced cancers & - & Safe & 2 Responses (2PR) & 135 \\
\hline i & 23 & Colorectal & Chemo + BV & Safe & 13 Responses (13PR) & 140 \\
\hline i & 27 & Colorectal & Chemo + BV & Safe & 6 Responses (6PR) & 141 \\
\hline i & 30 & Colorectal & Chemo $+\mathrm{CX}$ & Safe & NA & 142 \\
\hline i & 24 & Lung & Chemo + BV & Safe & 14 Responses (1CR/13PR) & 143 \\
\hline i & 7 & Lymphoma & Rituximab & Safe & 3 Responses (2CR/1PR) & 144 \\
\hline II (RCT) & 213 & Lung & Chemo + BV & Safe & No anticancer activity ${ }^{\mathrm{a}}$ & 106 \\
\hline II (RCT) & 48 & Lymphoma & Rituximab & Safe & No anticancer activity ${ }^{a}$ & 107 \\
\hline
\end{tabular}

Abbreviations: BV, bevacizumab; chemo, chemotherapy; CR, complete response; CX, cetuximab; PR, partial response; $n$, number of patients enrolled; $\mathrm{NA}$, data about responses (efficacy) were not reported; RCT, randomized-controlled trials

${ }^{a}$ Anticancer activity was considered when the addition of the TRA demonstrated statistically significant activity compared with the standard therapy

non-Hodgkin's lymphomas comparing dulanermin/rituximab to rituximab alone. ${ }^{107}$ Unfortunately, neither study revealed a significant anticancer activity that could have been attributed to dulanermin in these therapeutic regimes.

Apart from dulanermin, several agonistic TRAIL-R1- and TRAIL-R2-specific antibodies have entered clinical trials with one of them (mapatumumab) targeting TRAIL-R1 and all others (conatumumab, lexatumumab, tigatuzumab and drozitumab, LBY-135) targeting TRAIL-R2 (Figure 4 and Tables 2 and 3). For all of them, anticancer activity was demonstrated in preclinical models. Therefore, clinical trials were launched revealing safety and broad tolerability for all of them, both alone and in combination with standard therapy. For tigatuzumab the results of one, for mapatumumab the results of two, and for conatumumab the results of five, RCTs are available, which were conducted in soft tissue sarcoma, multiple myeloma, colorectal, pancreatic and lung cancer. All of these studies were carried out in combination with chemotherapy or the proteasome inhibitor bortezomib compared with the respective standard therapy alone (Tables 2 and 3). However, although some positive trends were observed, no statistically significant anticancer activity was achieved by addition of any of these TRAs in any RCT.

In summary, throughout all clinical studies dulanermin and all agonistic TRAIL-R antibodies were well tolerated, yet only minimal anticancer activity, which has not been confirmed in RCTs to date, was achieved. Thus, whereas toxicity of the evaluated TRAs is currently not to be expected, additional measures will have to be taken to achieve significant antitumor activity with TRAIL-based therapies. 
Table 2 Results of mapatumumab, an agonistic antibodies targeting TRAIL-R1 in clinical trials

\begin{tabular}{|c|c|c|c|c|c|c|}
\hline \multicolumn{7}{|c|}{ Mapatumumab (HGS-ETR1) } \\
\hline Phase & $n$ & Cancer & Combination & Safety & Efficacy & Reference \\
\hline I & 49 & Advanced cancers & - & Safe & No responses & 145 \\
\hline I & 41 & Advanced cancers & - & Safe & No responses & 146 \\
\hline i & 49 & Advanced cancers & Chemo & Safe & 12 Responses (12PR) & 147 \\
\hline i & 27 & Advanced cancers & Chemo & Safe & 5 Responses (5PR) & 148 \\
\hline I/II & 40 & Lymphoma & - & Safe & 3 Responses (2CR/1PR) & 149 \\
\hline II & 38 & Colorectal & - & Safe & No responses & 150 \\
\hline II & 32 & Lung & - & Safe & No responses & 151 \\
\hline II (RCT) & 104 & Multiple myeloma & Bortezomib & Safe & No anticancer activity ${ }^{a}$ & 121 \\
\hline II (RCT) & 109 & Lung & Chemo & Safe & No anticancer activity & 152 \\
\hline
\end{tabular}

Abbreviations: chemo, chemotherapy; CR, complete response; $n$, number of patients enrolled; PR, partial response; RCT, randomized-controlled trial

${ }^{a}$ Anticancer activity was considered when the addition of the TRA demonstrated statistically significant activity compared with the standard therapy

Table 3 Results of TRAIL-R2-targeting agonistic antibodies in clinical trials

\begin{tabular}{|c|c|c|c|c|c|c|}
\hline Phase & $n$ & Cancer & Combination & Safety & Efficacy & Reference \\
\hline \multicolumn{7}{|c|}{ Conatumumab (AMG-655) } \\
\hline l & 37 & Advanced cancers & - & Safe & 1 Response (1PR) & 153 \\
\hline I & 18 & Advanced cancer & - & Safe & No responses & 154 \\
\hline I & 6 & Soft tissue sarcoma & Chemo & Safe & No responses & 155 \\
\hline i & 9 & Advanced cancers & Ganitumab & Safe & No responses & 156 \\
\hline i & 12 & Lung & Chemo & Safe & 4 Responses (1CR/3PR) & 157 \\
\hline $\mathrm{i}$ & 12 & Colorectal & Chemo & Safe & 5 Responses (5PR) & 158 \\
\hline I & 13 & Pancreatic & Chemo & Safe & 4 Responses (4PR) & 159 \\
\hline II (RCT) & 128 & Soft tissue sarcoma & Chemo & Safe & No anticancer activity ${ }^{a}$ & 155 \\
\hline II (RCT) & 172 & Lung & Chemo & Safe & No anticancer activity ${ }^{a}$ & 160 \\
\hline II (RCT) & 83 & Pancreatic & Chemo & Safe & No anticancer activity ${ }^{a}$ & 161 \\
\hline II (RCT) & 103 & Colorectal & Chemo & Safe & No anticancer activity ${ }^{\mathrm{a}}$ & 162 \\
\hline II (RCT) & 190 & Colorectal & Chemo + BV & Safe & No anticancer activity ${ }^{a}$ & 163 \\
\hline \multicolumn{7}{|c|}{ Lexatumumab (HGS-ETR2) } \\
\hline 1 & 37 & Advanced cancers & - & Safe & No responses & 164 \\
\hline i & 31 & Advanced cancers & - & Safe & No responses & 165 \\
\hline $\mathrm{i}$ & 41 & Advanced Cancers & Chemo & Safe & Partial responses & 166 \\
\hline 1 & 24 & Pediatric cancers & - & Safe & No responses & 167 \\
\hline \multicolumn{7}{|c|}{ Tigatuzumab (CS-1008) } \\
\hline & 17 & Carcinoma or lymphoma & - & Safe & No responses & 168 \\
\hline II & 61 & Pancreatic & Chemo & Safe & 8 Responses (8PR) & 169 \\
\hline II (RCT) & 97 & Lung & Chemo & Safe & No anticancer activity ${ }^{a}$ & 170 \\
\hline \multicolumn{7}{|c|}{ Drozitumab (PRO95780/apomap) } \\
\hline I & 9 & Colorectal & Chemo & Safe & 2 Responses (2PR) & 171 \\
\hline $\mathrm{i}$ & 50 & Advanced cancers & - & Safe & No responses & 172 \\
\hline \multicolumn{7}{|l|}{$L B Y-135$} \\
\hline $\mathrm{I} / \mathrm{II}$ & 73 & Advanced cancers & Chemo & Safe & 2 Responses (2PR) & 173 \\
\hline
\end{tabular}

Abbreviations: BV, bevacizumab; chemo, chemotherapy; CR, complete response; $n$, number of patients enrolled; PR, partial response; RCT, randomized-controlled trial

${ }^{a}$ Anticancer activity was considered when the addition of the TRA demonstrated statistically significant activity compared with standard therapy

\section{Future Direction to get TRAIL Back on Track for Cancer Therapy}

Given the promising preclinical results, the failure of the TRAs that have thus far been tested clinically to exert robust anticancer activity in patients is disappointing. Nonetheless, if it were possible to identify the pitfalls of current TRA-based treatment approaches, it should be feasible to overcome these by novel strategies.

Development of highly active TRAs. In addition to dulanermin, several other recombinant TRAIL preparations have been developed in which the amino terminus of the TNF homology domain of TRAIL was fused to tags such as polyhistidine (His), Flag, leucine Zipper (LZ) and isoleucine zipper (iz) tags. Although the first two tags merely serve a purpose in purification of the recombinant protein, addition of the LZ and iz sequence results in stabilization of TRAIL trimers via hydrophobic interactions within the trimerizing LZ and iz sequences. ${ }^{21,108}$ Trimer stabilization results in increased agonistic activity of LZ- and iz-TRAIL as compared with other forms of TRAIL. ${ }^{108}$ Raising concern for some of these TRAIL variants, His-TRAIL and antibody-crosslinked Flag-TRAIL were shown to induce apoptosis in primary 
human hepatocytes in vitro, ${ }^{108,109}$ whereas LZ- and iz-TRAIL were found to be non-toxic to human hepatocytes and can be safely applied in vivo. ${ }^{21,108,110}$ In conclusion, non-tagged soluble TRAIL has been shown to have the lowest antitumor efficiency, but on the other hand, also the lowest potential for toxicity. The latter was presumably one of the reasons why non-tagged recombinant TRAIL, dulanermin, was selected for clinical development.

Agonistic TRAIL-R antibodies are per se rather weak inducers of apoptosis, which is due to the fact that for efficient apoptosis induction via DRs their trimerization is required. The inherent bivalent nature of antibodies, however, only allows for crosslinking of two DRs. Thereby, only inefficient DISC formation is achieved, and further crosslinking of antibodies is required for efficient antibody-induced DISC formation. ${ }^{111,112}$ This phenomenon has been intensively studied in the CD95 system since the early 1990s. ${ }^{113}$ Based on these considerations, the LZ- and iz-tagged forms of TRAIL were devised early on ${ }^{21,108}$ but not considered for clinical development at the time for the above-mentioned concerns over potential toxicity of high-activity forms of recombinant TRAIL.

Yet, novel TRAs capable of forming stable higher-order complexes are currently developed (reviewed by Holland ${ }^{114}$ ). Among other approaches, TRAIL was fused to the Fc portion of human IgG1 (Fc-TRAIL), resulting in an increased capacity to oligomerize and a prolonged half-live in vivo as compared with soluble TRAIL. Importantly, FC-TRAIL showed higher potency in inducing apoptosis in cancer cells in vitro and in vivo without exerting hepatotoxicity. ${ }^{115}$ Furthermore, a compound in which two trimers of the extracellular domain of TRAIL are fused to an Fc-part of human IgG1 generating a hexavalent TRA has recently been developed (APG350). ${ }^{116}$ APG350 demonstrated potent apoptosis induction in cancer cell lines, primary cancer cells and in xenograft mouse models. In addition, a novel tetrameric TRAIL-R2-activating nanobody, TAS266, has been developed for clinical use. TAS266 has been reported to be more effective than soluble TRAIL or agonistic antibodies in vitro and in vivo. ${ }^{117}$ However, it appears that a phase I clinical study with TAS266 in patients with advanced solid tumors was terminated early (clinicaltrials.gov). Although to date the reason for early termination of this study has not been disclosed, it raises concerns about the potential toxicity of this compound. In summary, first preclinical results obtained with these novel TRAs are promising, yet only clinical testing can ultimately reveal whether this promise will hold.

\section{Identification of potent and cancer-selective TRAIL sensitizers}

Conventional chemotherapy and bortezomib in combination with TRAIL: The use of more active TRAs is likely to result in significantly enhanced activity against cancer cells that are susceptible to TRAIL-induced apoptosis. However, many cancer cells are intrinsically TRAIL resistant, ${ }^{118}$ indicating that crucial roadblocks in the form of resistance factors will need to be removed from the TRAIL apoptosis pathway in these cells in order to kill them by TRAIL. To date, a multitude of publications has demonstrated sensitization of cancer cell lines to TRAIL-induced apoptosis. However, many of these studies do not provide evidence for therapeutic activity in vivo and, thereby, also neglect potential toxicity. Thus, the use of such TRAIL-sensitizing strategies should be carefully evaluated for both efficiency and toxicity in vivo before consideration for clinical use.

Most commonly used standard chemotherapeutic agents including gemcitabine, irinotecan, doxorubicin, 5-FU and platinum-based agents such as cisplatin have been shown to synergize with TRAIL (reviewed in Newsom-Davis et al ${ }^{119}$ ). Various mechanisms have been proposed to underlie chemotherapy-induced TRAIL sensitization including increased DISC formation, upregulation of pro-apoptotic and suppression of anti-apoptotic proteins including of the pro- and potentially anti-apoptotic TRAIL-Rs. These findings provided the rationale to combine TRAs with conventional chemotherapy also in clinical trials. As explained above, none of the RCTs conducted to date, however, showed clinical activity attributable to the respective TRAs (Tables 1, 2 and 3).

Bortezomib, which is used in multiple myeloma treatment, shows antitumor activity alone and in combination with TRAs in vitro and/or in vivo in a broad range of cancers, including multiple myeloma, hepatocellular, breast, lung and pancreatic cancer (reviewed in de Wilt et al ${ }^{120}$ ). Yet, a recently completed RCT testing treatment of multiple myeloma with bortezomib as compared with bortezomib plus the TRAIL-R1-targeting TRA mapatumumab showed no additive therapeutic benefit. ${ }^{121}$ However, this may be due to the fact that mapatumumab bears the intrinsic crosslinking limitation of antibodies explained above, at least in the absence of sufficient Fc $\gamma$ receptors in the vicinity of the tumor cells that could render this antibody active. ${ }^{111,112}$ In summary, to date clinically available TRAs did not achieve additional clinical activity in combination with chemotherapy or bortezomib. Of note, the lack in efficacy of these combinations might be due to insufficient agonistic activity of the respective TRA employed, insufficient sensitization to TRAIL-induced apoptosis by the applied co-therapy, or indeed the combination of these two shortcomings. It will hence be interesting to test whether enhanced clinical activity can be achieved by combining potent TRAIL-sensitizing treatments with high-activity TRAs.

Smac und BH3 mimetics in combination with TRAIL: IAPS represent attractive targets for cancer therapy since high IAP expression is found in many cancers, which is associated with tumor progression and therapy resistance (reviewed by Fulda $^{122}$ ). Hence, small molecules have been developed which mimic the XIAP-binding site of the endogenous XIAPantagonist Smac, thereby antagonizing IAPS. This class of agents named Smac mimetics or IAP antagonists has shown promising preclinical activity alone or in combination with anticancer agents, which initiated the development of these small-molecule compounds for clinical application. Currently, a number of phase I and II clinical studies testing different Smac mimetic alone or in combination with chemotherapy are under way. Intriguingly, Smac mimetics have shown broad preclinical activity in sensitizing cancer cells to TRAILinduced apoptosis in vitro and in vivo in a variety of cancer entities, ${ }^{123-126}$ rendering them promising candidates for efficient TRA-comprising therapeutic approaches. Therefore, a clinical trial in ovarian cancer patients has been launched, which tests efficacy of the Smac mimetic birinapant in combination with the TRAIL-R2 agonist conatumumab 
(clinicaltrials.gov). Results of this trial will show whether the promising preclinical results will be translated into clinical activity.

As mentioned above, intrinsic resistance to the mitochondrial apoptosis pathway caused by high expression of antiapoptotic Bcl-2 family members, such as Bcl-2, Bcl-xL and $\mathrm{Mcl}-1$, is a common feature of cancer cells and associated with chemoresistance. To overcome mitochondrial apoptosis resistance, $\mathrm{BH} 3$ mimetics have been developed to antagonize anti-apoptotic Bcl-2 family members. To date, two such compounds have been evaluated in the clinic: ABT-199, which specifically targets Bcl-2, and ABT-263 (Navitoclax), which antagonizes both $\mathrm{BCl}-2$ and $\mathrm{BCl}-\mathrm{xL} .{ }^{127,128} \mathrm{BH} 3$ mimetics have demonstrated impressive clinical activity in single therapy, and recently $\mathrm{Bcl}-2 / \mathrm{xL}$ inhibition by $\mathrm{ABT}-263$, or its non-orally available analog ABT-737, has been shown to sensitize cancer cells to TRAIL in vitro. ${ }^{129-131}$ Thus, $\mathrm{BH} 3$ and Smac mimetics can be used to sensitize cancer cells to TRAIL-induced apoptosis by selectively inhibiting important roadblocks that obstruct the TRAIL apoptosis pathway.

Cyclin-dependent kinase 9 (CDK9) inhibition and TRAIL: Small-molecule inhibitors of several kinases are an emerging class of cancer drugs based on the fact that cancer cells have elevated kinase activity to enhance proliferation, migration and invasion, but also to maintain apoptosis resistance. ${ }^{132}$ We recently discovered selective inhibition of CDK $9^{133}$ as the most powerful approach to overcome TRAIL resistance of cancer cells that we have come across in more than a decade of searching for potent TRAIL-sensitizing strategies. ${ }^{110}$ Intriguingly, CDK9 inhibition sensitizes cancer cells irrespective of their p53 status and can be applied together with a highly active recombinant form of TRAIL (iz-TRAIL) without causing hepatotoxicity within a considerable therapeutic window. Furthermore, the potency of this novel combination was underlined by the fact that it eradicated established orthotopic lung tumors in vivo. Mechanistically, CDK9 inhibition led to concomitant downregulation of cFLIP and $\mathrm{Mcl}-1$ and, together, these two events were both required and sufficient for CDK9 inhibition-mediated TRAIL sensitization. The therapeutic principle that emerges from these findings is that simultaneous removal of multiple resistance factors is required to overcome TRAIL resistance and to efficiently kill cancer cells by TRAIL-comprising therapeutic combinations. This concept should be taken into account when devising future TRAIL-based cancer therapies.

In summary, besides conventional chemotherapy and proteasome inhibition, several novel, more-selective pharmacological approaches are at hand, which exert promising preclinical activity in combination with TRAIL. For the establishment of an active but non-toxic TRAIL-based therapeutic regime it will be decisive to evaluate these different compounds, also in combination, in conjunction with second-generation TRAs that exhibit higher agonistic activity than their predecessors.

Identification of biomarkers that predict sensitivity to novel TRAIL-based therapies. It is interesting to note that among the majority of non-responding patients, in a subset of patients, TRAs showed signs of therapeutic benefit. These included two patients with chondrosarcoma, a cancer entity which is known to be largely resistant to conventional therapies. Intriguingly, both patients showed an antitumor response upon dulanermin monotherapy and in one of them long-term survival was achieved by combining surgery and prolonged dulanermin treatment. ${ }^{134,135}$ These case reports reveal that recombinant forms of TRAIL, and possibly other TRAs, can be beneficial for individual patients even without additional sensitization strategies. However, so far it remains widely unresolved which markers, in addition to TRAIL-R1/2 expression, would identify and allow selection of patients that are likely to benefit from a TRA-comprising therapy. One report identified high expression of the O-glycosylation enzyme GALNT14 as a signature of TRAIL sensitivity in cancer cells. Mechanistically, the study showed that glycosylation of TRAIL-R2 leads to enhanced ligand-induced receptor clustering, facilitated DISC formation and subsequent apoptosis induction. ${ }^{136}$ Nevertheless, the value of using GALNT14 expression for predicting TRAIL sensitivity in patients remains to be shown as increased GALNT14 expression did not appear to significantly correlate with clinical response to dulanermin in a clinical study. ${ }^{106}$ In another approach, cell lines were systematically screened for responsiveness to TRAIL and, in parallel, expression of a panel of factors involved in executing or inhibiting the extrinsic apoptosis pathway was quantified. Data extracted from these results enabled predicting responsiveness to TRAIL. Possibly even more interestingly from a clinical perspective, the authors could utilize their system to propose a case-specific TRAIL-sensitizing strategy by analyzing the expression profiles from individual cell lines. ${ }^{137}$ Although these findings will require further validation in primary cancer cells and in vivo, this new and promising approach could prove to be valuable, given the recent advances in quantitative proteomics, which could enable the determination of protein expression profiles from patient-derived cancer tissue.

\section{Conclusion and Outlook}

At the turn of the millennium, the discovery of TRAIL and its capacity to induce apoptosis selectively in tumor cells sparked the development of TRAIL and other TRAs as potential novel cancer drugs. Since then, the TRAIL signaling cascade has been the subject of intense research. However, 15 years on, first-generation TRAs could not live up to high expectations in clinical trials. The possible pitfalls have been identified, as outlined above, and strategies to tackle these are intensively investigated. Novel TRAs with increased agonistic properties are currently developed and high-potency, cancer-selective TRAIL sensitizers are appearing at the horizon. It is important to note that all preclinical in-vivo studies preceding the decision to start clinical trials with current TRAs were performed in xenograft or syngeneic graft mouse models. At the time, these were the standard mouse models available and have been helpful in evaluating preclinical activity of many anticancer therapies in the past. It has, however, become evident that these models lack many crucial aspects of the systemic disease that is cancer. This shortcoming has been addressed by the development of genetically engineered 
mouse models of various cancers, which closely resemble the full clinical spectra of the respective human cancers. ${ }^{138,139}$ Hence, the challenge now is to determine whether newly devised high-activity TRAs combined with the most potent TRAIL-sensitizing strategies exert a therapeutic effect in these sophisticated mouse models of cancer to ultimately get TRAIL back on track to the cancer clinic.

\section{Conflict of Interest}

$\mathrm{HW}$ is a named inventor on the patent that formed the basis for the development of Conatumumab. HW is cofounder, scientific advisor and shareholder of Apogenix GmbH (Heidelberg, Germany), a company that develops apoptosis-based drugs, including the TRAIL-R agonist APG350. The remaining authors declare no conflict of interest.

Acknowledgements. This work was supported by a Cancer Research UK programme grant (C33499/A10950) awarded to HW and a postdoctoral fellowship from the Dr. Mildred-Scheel Stiftung/Deutsche Krebshilfe awarded to JL.

1. Hanahan D, Weinberg RA. Hallmarks of cancer: the next generation. Cell 2011; 144 646-674.

2. Galluzi L, Kepp O, Kroemer G. Mitochondria: master regulators of danger signalling. Nat Rev. Mol Cell Biol 2012; 13: 780-788.

3. Green DR, Kroemer G. The pathophysiology of mitochondrial cell death. Science 2004; 305: 626-629.

4. Lowe SW, Bodis S, McClatchey A, Remington L, Ruley HE, Fisher DE et al. p53 status and the efficacy of cancer therapy in vivo. Science 1994; 266: 807-810.

5. Olivier M, Hollstein M, Hainaut P. TP53 mutations in human cancers: origins, consequences, and clinical use. Cold Spring Harb Perspect Biol 2010; 2: a001008.

6. Schilling T, Schleithoff ES, Kairat A, Melino G, Stremmel W, Oren M et al. Active transcription of the human FAS/CD95/TNFRSF6 gene involves the p53 family. Biochem Biophys Res Commun 2009; 387: 399-404.

7. Wu GS, Burns TF, McDonald ER III, Jiang W, Meng R, Krantz ID et al. KILLER/DR5 is a DNA damage-inducible p53-regulated death receptor gene. Nat Genet 1997; 17 141-143.

8. O'Connor L, Harris AW, Strasser A. CD95 (Fas/APO-1) and p53 signal apoptosis independently in diverse cell types. Cancer Res 2000; 60: 1217-1220.

9. Carswell EA, Old LJ, Kassel RL, Green S, Fiore N, Williamson B. An endotoxin-induced serum factor that causes necrosis of tumors. Proc Natl Acad Sci USA 1975; 72 3666-3670.

10. Roberts NJ, Zhou S, Diaz Jr LA, Holdhoff M. Systemic use of tumor necrosis factor alpha as an anticancer agent. Oncotarget 2011; 2: 739-751.

11. Tracey KJ, Lowry SF, Cerami A. Cachetin/TNF-alpha in septic shock and septic adult respiratory distress syndrome. Am Rev Respir Dis 1988; 138: 1377-1379.

12. Tracey KJ, Lowry SF, Fahey 3rd TJ, Albert JD, Fong Y, Hesse D et al. Cachectin/tumor necrosis factor induces lethal shock and stress hormone responses in the dog. Surg Gynecol Obstet 1987; 164: 415-422.

13. Trauth BC, Klas C, Peters AM, Matzku S, Moller P, Falk W et al. Monoclonal antibodymediated tumor regression by induction of apoptosis. Science 1989; 245: 301-305.

14. Yonehara S, Ishii A, Yonehara M. A cell-killing monoclonal antibody (anti-Fas) to a cell surface antigen co-downregulated with the receptor of tumor necrosis factor. J Exp Med 1989; 169: 1747-1756

15. Itoh N, Yonehara S, Ishii A, Yonehara M, Mizushima S, Sameshima M et al. The polypeptide encoded by the cDNA for human cell surface antigen Fas can mediate apoptosis. Cell 1991; 66: 233-243.

16. Oehm A, Behrmann I, Falk W, Pawlita M, Maier G, Klas $C$ et al. Purification and molecular cloning of the APO-1 cell surface antigen, a member of the tumor necrosis factor/nerve growth factor receptor superfamily. Sequence identity with the Fas antigen. J Biol Chem 1992; 267: 10709-10715.

17. Ogasawara J, Watanabe-Fukunaga R, Adachi M, Matsuzawa A, Kasugai T, Kitamura Y et al. Lethal effect of the anti-Fas antibody in mice. Nature 1993; 364: 806-809.

18. Pitti RM, Marsters SA, Ruppert S, Donahue CJ, Moore A, Ashkenazi A. Induction of apoptosis by Apo-2 ligand, a new member of the tumor necrosis factor cytokine family. J Biol Chem 1996; 271: 12687-12690.

19. Wiley SR, Schooley K, Smolak PJ, Din WS, Huang CP, Nicholl JK et al. Identification and characterization of a new member of the TNF family that induces apoptosis. Immunity 1995; 3: 673-682.

20. Ashkenazi A, Pai RC, Fong S, Leung S, Lawrence DA, Marsters SA et al. Safety and antitumor activity of recombinant soluble Apo2 ligand. J Clin Invest 1999; 104: 155-162.
21. Walczak H, Miller RE, Ariail K, Gliniak B, Griffith TS, Kubin M et al. Tumoricidal activity of tumor necrosis factor-related apoptosis-inducing ligand in vivo. Nat Med 1999; 5: 157-163.

22. Pan G, O'Rourke K, Chinnaiyan AM, Gentz R, Ebner R, Ni J et al. The receptor for the cytotoxic ligand TRAIL. Science 1997; 276: 111-113.

23. Pan G, Ni J, Wei YF, Yu G, Gentz R, Dixit VM. An antagonist decoy receptor and a death domain-containing receptor for TRAIL. Science 1997; 277: 815-818.

24. Screaton GR, Mongkolsapaya J, Xu XN, Cowper AE, McMichael AJ, Bell JI. TRICK2, a new alternatively spliced receptor that transduces the cytotoxic signal from TRAIL. Curr Biol 1997; 7: 693-696.

25. Sheridan JP, Marsters SA, Pitti RM, Gurney A, Skubatch M, Baldwin D et al. Control of TRAIL-induced apoptosis by a family of signaling and decoy receptors. Science 1997; 277: 818-821.

26. Walczak H, Degli-Esposti MA, Johnson RS, Smolak PJ, Waugh JY, Boiani N et al. TRAIL-R2:a novel apoptosis-mediating receptor for TRAIL. EMBO J 1997; 16: 5386-5397.

27. Kischkel FC, Lawrence DA, Chuntharapai A, Schow P, Kim KJ, Ashkenazi A Apo2L/TRAIL-dependent recruitment of endogenous FADD and caspase-8 to death receptors 4 and 5. Immunity 2000; 12: 611-620.

28. Kischkel FC, Lawrence DA, Tinel A, LeBlanc H, Virmani A, Schow $P$ et al. Death receptor recruitment of endogenous caspase- 10 and apoptosis initiation in the absence of caspase-8. J Biol Chem 2001; 276: 46639-46646.

29. Sprick MR, Rieser E, Stahl H, Grosse-Wilde A, Weigand MA, Walczak H. Caspase-10 is recruited to and activated at the native TRAIL and CD95 death-inducing signalling complexes in a FADD-dependent manner but can not functionally substitute caspase-8. EMBO J 2002; 21: 4520-4530.

30. Sprick MR, Weigand MA, Rieser E, Rauch CT, Juo P, Blenis J et al. FADD/MORT1 and caspase- 8 are recruited to TRAIL receptors 1 and 2 and are essential for apoptosis mediated by TRAIL receptor 2. Immunity 2000; 12: 599-609.

31. Kantari $\mathrm{C}$, Walczak $\mathrm{H}$. Caspase-8 and bid: caught in the act between death receptors and mitochondria. Biochimica et Biophysica Acta 2011; 1813: 558-563.

32. Dickens LS, Boyd RS, Jukes-Jones R, Hughes MA, Robinson GL, Fairall $L$ et al. A death effector domain chain DISC model reveals a crucial role for caspase-8 chain assembly in mediating apoptotic cell death. Mol Cell 2012; 47: 291-305.

33. Schleich K, Warnken U, Fricker N, Ozturk S, Richter P, Kammerer K et al. Stoichiometry of the CD95 death-inducing signaling complex: experimental and modeling evidence for a death effector domain chain model. Mol Cell 2012; 47: 306-319.

34. Degli-Esposti MA, Smolak PJ, Walczak H, Waugh J, Huang CP, DuBose RF et al. Cloning and characterization of TRAIL-R3, a novel member of the emerging TRAIL receptor family. J Exp Med 1997; 186: 1165-1170.

35. Mongkolsapaya J, Cowper AE, Xu XN, Morris G, McMichael AJ, Bell Jl et al. Lymphocyte inhibitor of TRAIL (TNF-related apoptosis-inducing ligand): a new receptor protecting lymphocytes from the death ligand TRAIL. J Immunol 1998; 160: 3-6.

36. Schneider P, Bodmer JL, Thome M, Hofmann K, Holler N, Tschopp J. Characterization of two receptors for TRAIL. FEBS Lett 1997; 416: 329-334

37. Degli-Esposti MA, Dougall WC, Smolak PJ, Waugh JY, Smith CA, Goodwin RG. The novel receptor TRAIL-R4 induces NF-kappaB and protects against TRAIL-mediated apoptosis, yet retains an incomplete death domain. Immunity 1997; 7: 813-820.

38. Marsters SA, Sheridan JP, Pitti RM, Huang A, Skubatch M, Baldwin D et al. A novel receptor for Apo2L/TRAIL contains a truncated death domain. Curr Biol 1997; 7: 1003-1006.

39. Pan G, Ni J, Yu G, Wei YF, Dixit VM. TRUNDD, a new member of the TRAIL receptor family that antagonizes TRAIL signalling. FEBS Lett 1998; 424: 41-45.

40. Merino D, Lalaoui N, Morizot A, Schneider P, Solary E, Micheau O. Differential inhibition of TRAIL-mediated DR5-DISC formation by decoy receptors 1 and 2. Mol Cell Biol 2006; 26: 7046-7055

41. Morizot A, Merino D, Lalaoui N, Jacquemin G, Granci V, lessi E et al. Chemotherapy overcomes TRAIL-R4-mediated TRAIL resistance at the DISC level. Cell Death Differ 2011; 18: 700-711.

42. Clancy L, Mruk K, Archer K, Woelfel M, Mongkolsapaya J, Screaton G et al. Preligand assembly domain-mediated ligand-independent association between TRAIL receptor 4 (TR4) and TR2 regulates TRAIL-induced apoptosis. Proc Natl Acad Sci USA 2005; 102: 18099-18104.

43. Lalaoui N, Morle A, Merino D, Jacquemin G, lessi E, Morizot A et al. TRAIL-R4 promotes tumor growth and resistance to apoptosis in cervical carcinoma HeLa cells through AKT. PLoS One 2011; 6: e19679.

44. Sheikh MS, Huang Y, Fernandez-Salas EA, El-Deiry WS, Friess H, Amundson S et al. The antiapoptotic decoy receptor TRID/TRAIL-R3 is a p53-regulated DNA damageinducible gene that is overexpressed in primary tumors of the gastrointestinal tract. Oncogene 1999; 18: 4153-4159.

45. Ganten TM, Sykora J, Koschny R, Batke E, Aulmann S, Mansmann U et al. Prognostic significance of tumour necrosis factor-related apoptosis-inducing ligand (TRAIL) receptor expression in patients with breast cancer. J Mol Med (Berl) 2009; 87: 995-1007.

46. Lacey DL, Boyle WJ, Simonet WS, Kostenuik PJ, Dougall WC, Sullivan JK et al. Bench to bedside: elucidation of the OPG-RANK-RANKL pathway and the development of denosumab. Nature reviews. Drug Dis 2012; 11: 401-419. 
47. Emery JG, McDonnell P, Burke MB, Deen KC, Lyn S, Silverman C et al. Osteoprotegerin is a receptor for the cytotoxic ligand TRAIL. J Biol Chem 1998; 273: 14363-14367.

48. Miyashita T, Kawakami A, Nakashima T, Yamasaki S, Tamai M, Tanaka F et al. Osteoprotegerin (OPG) acts as an endogenous decoy receptor in tumour necrosis factorrelated apoptosis-inducing ligand (TRAIL)-mediated apoptosis of fibroblast-like synovial cells. Clin Exp Immunol 2004; 137: 430-436.

49. Shipman CM, Croucher PI. Osteoprotegerin is a soluble decoy receptor for tumor necrosis factor-related apoptosis-inducing ligand/Apo2 ligand and can function as a paracrine survival factor for human myeloma cells. Cancer Res 2003; 63: 912-916.

50. Truneh A, Sharma S, Silverman C, Khandekar S, Reddy MP, Deen KC et al. Temperature-sensitive differential affinity of TRAIL for its receptors. DR5 is the highest affinity receptor. J Biol Chem 2000; 275: 23319-23325.

51. Wu GS, Burns TF, Zhan Y, Alnemri ES, El-Deiry WS. Molecular cloning and functional analysis of the mouse homologue of the KILLER/DR5 tumor necrosis factor-related apoptosis-inducing ligand (TRAIL) death receptor. Cancer Res 1999; 59: 2770-2775.

52. Schneider P, Olson D, Tardivel A, Browning B, Lugovskoy A, Gong D et al. Identification of a new murine tumor necrosis factor receptor locus that contains two novel murine receptors for tumor necrosis factor-related apoptosis-inducing ligand (TRAIL). J Biol Chem 2003; 278: 5444-5454.

53. Jin Z, Li Y, Pitti R, Lawrence D, Pham VC, Lill JR et al. Cullin3-based polyubiquitination and p62-dependent aggregation of caspase- 8 mediate extrinsic apoptosis signaling. Cell 2009; 137: 721-735.

54. Gonzalvez F, Lawrence D, Yang B, Yee S, Pitti R, Marsters S et al. TRAF2 Sets a threshold for extrinsic apoptosis by tagging caspase-8 with a ubiquitin shutoff timer. $\mathrm{Mol}$ Cell 2012; 48: 888-899.

55. Vince JE, Pantaki D, Feltham R, Mace PD, Cordier SM, Schmukle AC et al. TRAF2 must bind to cellular inhibitors of apoptosis for tumor necrosis factor (tnf) to efficiently activate nf-\{kappa\}b and to prevent tnf-induced apoptosis. J Biol Chem 2009; 284: 35906-35915.

56. Yin Q, Lamothe B, Darnay BG, Wu H. Structural basis for the lack of E2 interaction in the RING domain of TRAF2. Biochemistry 2009; 48: 10558-10567.

57. Scaffidi C, Fulda S, Srinivasan A, Friesen C, Li F, Tomaselli KJ et al. Two CD95 (APO-1/Fas) signaling pathways. EMBO J 1998; 17: 1675-1687.

58. Schug ZT, Gonzalvez F, Houtkooper RH, Vaz FM, Gottlieb E. BID is cleaved by caspase-8 within a native complex on the mitochondrial membrane. Cell Death Differ 2011; 18: 538-548.

59. Westphal D, Kluck RM, Dewson G. Building blocks of the apoptotic porehow Bax and Bak are activated and oligomerize during apoptosis. Cell Death Differ 2014; 21: 196-205.

60. Peter ME, Krammer PH. Mechanisms of CD95 (APO-1/Fas)-mediated apoptosis. Curr Opin Immunol 1998; 10: 545-551.

61. Jost PJ, Grabow S, Gray D, McKenzie MD, Nachbur U, Huang DC et al. XIAP discriminates between type I and type II FAS-induced apoptosis. Nature 2009; 460: $1035-1039$.

62. Deveraux QL, Takahashi R, Salvesen GS, Reed JC. X-linke IAP is a direct inhibitor of celldeath proteases. Nature 1997; 388: 300-304.

63. Linkermann A, Green DR. Necroptosis. N Engl J Med 2014; 370: 455-465.

64. Sun L, Wang H, Wang Z, He S, Chen S, Liao D et al. Mixed lineage kinase domain-like protein mediates necrosis signaling downstream of RIP3 kinase. Cell 2012; 148: 213-227.

65. Murphy JM, Czabotar PE, Hildebrand JM, Lucet IS, Zhang JG, Alvarez-Diaz S et al. The pseudokinase MLKL mediates necroptosis via a molecular switch mechanism. Immunity 2013; 39: 443-453.

66. Cai Z, Jitkaew S, Zhao J, Chiang HC, Choksi S, Liu J et al. Plasma membrane translocation of trimerized MLKL protein is required for TNF-induced necroptosis. Nat Cell Biol 2014; 16: 55-65.

67. Chen X, Li W, Ren J, Huang D, He WT, Song Y et al. Translocation of mixed lineage kinase domain-like protein to plasma membrane leads to necrotic cell death. Cell Res 2014; 24: 105-121.

68. Holler N, Zaru R, Micheau O, Thome M, Attinger A, Valitutti S et al. Fas triggers an alternative, caspase-8-independent cell death pathway using the kinase RIP as effector molecule. Nat Immunol 2000; 1: 489-495.

69. Jouan-Lanhouet S, Arshad MI, Piquet-Pellorce C, Martin-Chouly C, Le Moigne-Muller G, Van Herreweghe $\mathrm{F}$ et al. TRAIL induces necroptosis involving RIPK1/RIPK3-dependent PARP-1 activation. Cell Death Differ 2012; 19: 2003-2014

70. Voigt S, Philipp S, Davarnia P, Winoto-Morbach S, Roder C, Arenz C et al. TRAILinduced programmed necrosis as a novel approach to eliminate tumor cells. BMC Cancer 2014; $14: 74$

71. Geserick P, Hupe M, Moulin M, Wong WW, Feoktistova M, Kellert B et al. Cellular IAPs inhibit a cryptic CD95-induced cell death by limiting RIP1 kinase recruitment. J Cell Biol 2009; 187: 1037-1054.

72. Golks A, Brenner D, Fritsch C, Krammer PH, Lavrik IN. c-FLIPR, a new regulator of death receptor-induced apoptosis. J Biol Chem 2005; 280: 14507-14513.

73. Krueger A, Schmitz I, Baumann S, Krammer PH, Kirchhoff S. Cellular FLICE-inhibitory protein splice variants inhibit different steps of caspase-8 activation at the CD95 deathinducing signaling complex. J Biol Chem 2001; 276: 20633-20640.

74. Ozturk S, Schleich K, Lavrik IN. Cellular FLICE-like inhibitory proteins (c-FLIPs): fine-tuners of life and death decisions. Exp Cell Res 2012; 318: 1324-1331.
75. Chang DW, Xing Z, Pan Y, Algeciras-Schimnich A, Barnhart BC, Yaish-Ohad S et al. c-FLIP $(L)$ is a dual function regulator for caspase-8 activation and CD95-mediated apoptosis. EMBO J 2002; 21: 3704-3714.

76. Micheau O, Thome M, Schneider P, Holler N, Tschopp J, Nicholson DW et al. The long form of FLIP is an activator of caspase-8 at the Fas death-inducing signaling complex. J Biol Chem 2002; 277: 45162-45171.

77. Feoktistova M, Geserick P, Kellert B, Dimitrova DP, Langlais C, Hupe M et al. clAPs block ripoptosome formation, a RIP1/caspase-8 containing intracellular cell death complex differentially regulated by cFLIP isoforms. Mol Cell 2011; 43: 449-463.

78. Oberst A, Dillon CP, Weinlich R, McCormick LL, Fitzgerald P, Pop C et al. Catalytic activity of the caspase-8-FLIP $(\mathrm{L})$ complex inhibits RIPK3-dependent necrosis. Nature 2011; 471: 363-367.

79. Shamas-Din A, Kale J, Leber B, Andrews DW. Mechanisms of action of Bcl-2 family proteins. Cold Spring Harb Perspect Biol 2013; 5: a008714.

80. Westphal D, Dewson G, Czabotar PE, Kluck RM. Molecular biology of Bax and Bak activation and action. Biochimica et Biophysica Acta 2011; 1813: 521-531.

81. Indran IR, Tufo G, Pervaiz S, Brenner C. Recent advances in apoptosis, mitochondria and drug resistance in cancer cells. Biochimica et Biophysica Acta 2011; 1807: 735-745.

82. LeBlanc H, Lawrence D, Varfolomeev E, Totpal K, Morlan J, Schow P et al. Tumor-cell resistance to death receptor-induced apoptosis through mutational inactivation of the proapoptotic Bcl-2 homolog Bax. Nat Med 2002; 8: 274-281.

83. Munshi A, Pappas G, Honda T, McDonnell TJ, Younes A, Li Y et al. TRAIL (APO-2L) induces apoptosis in human prostate cancer cells that is inhibitable by $\mathrm{Bcl}-2$. Oncogene 2001; 20: 3757-3765.

84. Hinz S, Trauzold A, Boenicke L, Sandberg C, Beckmann S, Bayer E et al. Bcl-XL protects pancreatic adenocarcinoma cells against CD95- and TRAlL-receptor-mediated apoptosis. Oncogene 2000; 19: 5477-5486.

85. Clohessy JG, Zhuang J, de Boer J, Gil-Gomez G, Brady HJ. Mcl-1 interacts with truncated $B i d$ and inhibits its induction of cytochrome $c$ release and its role in receptor-mediated apoptosis. J Biol Chem 2006; 281: 5750-5759.

86. Verhagen AM, Ekert PG, Pakusch M, Silke J, Connolly LM, Reid GE et al. Identification of DIABLO, a mammalian protein that promotes apoptosis by binding to and antagonizing IAP proteins. Cell 2000; 102: 43-53.

87. Eckelman BP, Salvesen GS. The human anti-apoptotic proteins CIAP1 and cIAP2 bind but do not inhibit caspases. J Biol Chem 2006; 281: 3254-3260.

88. Vaux DL, Silke J. IAPs-the ubiquitin connection. Cell Death Differ 2005; 12: 1205-1207.

89. Vaux DL, IAPs Silke J. RINGs and ubiquitylation. Nature reviews. Mol Cell Biol 2005; 6: 287-297.

90. Yang Y, Fang S, Jensen JP, Weissman AM, Ashwell JD. Ubiquitin protein ligase activity of IAPs and their degradation in proteasomes in response to apoptotic stimuli. Science 2000; 288: 874-877.

91. Choi YE, Butterworth M, Malladi S, Duckett CS, Cohen GM, Bratton SB. The E3 ubiquitin ligase CIAP1 binds and ubiquitinates caspase- 3 and -7 via unique mechanisms at distinct steps in their processing. J Biol Chem 2009; 284: 12772-12782.

92. Gyrd-Hansen M, Meier P. IAPs: from caspase inhibitors to modulators of NF-kappaB, inflammation and cancer. Nat Rev Cancer 2010; 10: 561-574.

93. Silke J, Meier P. Inhibitor of apoptosis (IAP) proteins-modulators of cell death and inflammation. Cold Spring Harb Perspect Biol 2013; 5: pii: a008730.

94. Azijli K, Weyhenmeyer B, Peters GJ, de Jong S, Kruyt FA. Non-canonical kinase signaling by the death ligand TRAIL in cancer cells: discord in the death receptor family. Cell Death Differ 2013; 20: 858-868.

95. Ishimura N, Isomoto H, Bronk SF, Gores GJ. Trail induces cell migration and invasion in apoptosis-resistant cholangiocarcinoma cells. Am J Physiol Gastrointest Liver Physiol 2006; 290: G129-G136

96. Trauzold A, Siegmund D, Schniewind B, Sipos B, Egberts J, Zorenkov D et al. TRAIL promotes metastasis of human pancreatic ductal adenocarcinoma. Oncogene 2006; 25: 7434-7439.

97. Haselmann V, Kurz A, Bertsch U, Hubner S, Olempska-Muller M, Fritsch J et al. Nuclear death receptor TRAILR2 inhibits maturation of Let-7 and promotes proliferation of pancreatic and other tumor cells. Gastroenterology 2013; 146: 278-290.

98. Hoogwater FJ, Nijkamp MW, Smakman N, Steller EJ, Emmink BL, Westendorp BF et al. Oncogenic K-Ras turns death receptors into metastasis-promoting receptors in human and mouse colorectal cancer cells. Gastroenterology 2010; 138: 2357-2367.

99. Balkwill F. Tumour necrosis factor and cancer. Nat Rev Cancer 2009; 9: 361-371.

100. Tuettenberg J, Seiz M, Debatin KM, Hollburg W, von Staden M, Thiemann M et al. Pharmacokinetics, pharmacodynamics, safety and tolerability of APG101, a CD95-Fc fusion protein, in healthy volunteers and two glioma patients. Int Immunopharmacol 2012 13: $93-100$.

101. Kelley RF, Totpal K, Lindstrom SH, Mathieu M, Billeci K, Deforge L et al. Receptor-selective mutants of apoptosis-inducing ligand 2/tumor necrosis factor-related apoptosis-inducing ligand reveal a greater contribution of death receptor (DR) 5 than DR4 to apoptosis signaling. J Biol Chem 2005; 280: 2205-2212.

102. MacFarlane M, Inoue S, Kohlhaas SL, Majid A, Harper N, Kennedy DB et al. Chronic lymphocytic leukemic cells exhibit apoptotic signaling via TRAIL-R1. Cell Death Differ 2005; 12: 773-782. 
103. MacFarlane M, Kohlhaas SL, Sutcliffe MJ, Dyer MJ, Cohen GM. TRAIL receptor-selective mutants signal to apoptosis via TRAIL-R1 in primary lymphoid malignancies. Cancer Res 2005; 65: 11265-11270.

104. Lemke J, Noack A, Adam D, Tchikov V, Bertsch U, Roder C et al. TRAIL signaling is mediated by DR4 in pancreatic tumor cells despite the expression of functional DR5. J Mol Med (Berl) 2010; 88: 729-740.

105. Wilson NS, Yang A, Yang B, Couto S, Stern H, Gogineni A et al. Proapoptotic activation of death receptor 5 on tumor endothelial cells disrupts the vasculature and reduces tumor growth. Cancer Cell 2012; 22: 80-90.

106. Soria JC, Mark Z, Zatloukal P, Szima B, Albert I, Juhasz E et al. Randomized phase II study of dulanermin in combination with paclitaxel, carboplatin, and bevacizumab in advanced non-small-cell lung cancer. J Clin Oncol 2011; 29: 4442-4451.

107. Belada DM, Mayer J, Czuczman MS, Flinn IW, Durbin-Johnson B, Bray GL. Phase I study of dulanermin plus rituximab in patients with relapsed follicular non-Hodgkin's lymphoma (NHL). J Clin Oncol 2010; 28: abstract 8104

108. Ganten TM, Koschny R, Sykora J, Schulze-Bergkamen H, Buchler P, Haas TL et al. Preclinical differentiation between apparently safe and potentially hepatotoxic applications of TRAIL either alone or in combination with chemotherapeutic drugs. Clin Cancer Res 2006; 12: 2640-2646.

109. Lawrence D, Shahrokh Z, Marsters S, Achilles K, Shih D, Mounho B et al. Differentia hepatocyte toxicity of recombinant Apo2L/TRAIL versions. Nat Med 2001; 7: 383-385.

110. Lemke J, von Karstedt S, Abd El Hay M, Conti A, Arce F, Montinaro A et al. Selective CDK9 inhibition overcomes TRAIL resistance by concomitant suppression of CFlip and Mcl-1. Cell Death Differ 2014; 21: 491-502.

111. Wilson NS, Yang B, Yang A, Loeser S, Marsters S, Lawrence D et al. An Fcgamma receptor-dependent mechanism drives antibody-mediated target-receptor signaling in cancer cells. Cancer Cell 2011; 19: 101-113.

112. Haynes NM, Hawkins ED, Li M, McLaughlin NM, Hammerling GJ, Schwendener R et al. $\mathrm{CD} 11 \mathrm{C}+$ dendritic cells and $\mathrm{B}$ cells contribute to the tumoricidal activity of anti-DR5 antibody therapy in established tumors. J Immunol 2010; 185: 532-541.

113. Dhein J, Daniel PT, Trauth BC, Oehm A, Moller P, Krammer PH. Induction of apoptosis by monoclonal antibody anti-APO-1 class switch variants is dependent on cross-linking of APO-1 cell surface antigens. J Immunol 1992; 149: 3166-3173.

114. Holland PM. Death receptor agonist therapies for cancer, which is the right TRAIL? Cytokine Growth Factor Rev 2013; 25: 185-193.

115. Wang $\mathrm{H}$, Davis JS, Wu X. Immunoglobulin Fc domain fusion to TRAIL significantly prolongs its plasma half-life and enhances its anti-tumor activity. Mol Cancer Ther 2014 13: 643-650.

116. Gieffers C, Kluge M, Merz C, Sykora J, Thiemann M, Schaal R et al. APG350 induces superior clustering of TRAIL receptors and shows therapeutic antitumor efficacy independent of cross-linking via fcgamma receptors. Mol Cancer Ther 2013; 12 2735-2747.

117. Huet H, Schuller A, Li J, Johnson J, Dombrecht B, Meerschaert K et al. TAS266, a novel tetrameric nanobody agonist targeting death receptor 5 (DR5), elicits superior antitumor efficacy than conventional DR5-targeted approaches. Cancer Res 2012; 72: abstrac 3853.

118. Todaro M, Lombardo Y, Francipane MG, Alea MP, Cammareri P, lovino F et al. Apoptosis resistance in epithelial tumors is mediated by tumor-cell-derived interleukin-4. Cell Death Differ 2008; 15: 762-772.

119. Newsom-Davis T, Prieske S, Walczak H. Is TRAIL the holy grail of cancer therapy? Apoptosis 2009; 14: 607-623.

120. de Wilt LH, Kroon J, Jansen G, de Jong S, Peters GJ, Kruyt FA. Bortezomib and TRAlL: a perfect match for apoptotic elimination of tumour cells? Crit Rev Oncol Hematol 2013; 85: 363-372.

121. Belch A, Sharma A, Spencer A, Tarantolo S, Bahlis N.J, Doval D et al. A multicenter randomized phase ii trial of mapatumumab, a TRAIL-R1 agonist monoclonal antibody, in combination with bortezomib in patients with relapsed/refractory multiple myeloma (MM) Blood 2010; 116: abstracts 5031

122. Fulda S. Molecular pathways: targeting inhibitor of apoptosis proteins in cancer-from molecular mechanism to therapeutic application. Clin Cancer Res 2013; 20: 289-295.

123. Fulda S, Wick W, Weller M, Debatin KM. Smac agonists sensitize for Apo2L/TRAIL- or anticancer drug-induced apoptosis and induce regression of malignant glioma in vivo. Nat Med 2002; 8: 808-815.

124. Li L, Thomas RM, Suzuki H, De Brabander JK, Wang X, Harran PG. A small molecule Smac mimic potentiates TRAIL- and TNFalpha-mediated cell death. Science 2004; 305 : $1471-1474$

125. Fakler M, Loeder S, Vogler M, Schneider K, Jeremias I, Debatin KM et al. Small molecule XIAP inhibitors cooperate with TRAIL to induce apoptosis in childhood acute leukemia cells and overcome Bcl-2-mediated resistance. Blood 2009; 113: 1710-1722.

126. Lecis D, Drago C, Manzoni L, Seneci P, Scolastico C, Mastrangelo E et al. Novel SMAC-mimetics synergistically stimulate melanoma cell death in combination with TRAIL and Bortezomib. Br J Cancer 2010; 102: 1707-1716.

127. Tse C, Shoemaker AR, Adickes J, Anderson MG, Chen J, Jin S et al. ABT-263: a potent and orally bioavailable Bcl-2 family inhibitor. Cancer Res 2008; 68: 3421-3428.

128. Souers AJ, Leverson JD, Boghaert ER, Ackler SL, Catron ND, Chen J et al. ABT-199, a potent and selective BCL-2 inhibitor, achieves antitumor activity while sparing platelets. Nat Med 2013; 19: 202-208
129. Huang S, Sinicrope FA. BH3 mimetic ABT-737 potentiates TRAIL-mediated apoptotic signaling by unsequestering Bim and Bak in human pancreatic cancer cells. Cancer Res 2008; 68: 2944-2951.

130. Cristofanon S, Fulda S. ABT-737 promotes tBid mitochondrial accumulation to enhance TRAIL-induced apoptosis in glioblastoma cells. Cell Death Dis 2012; 3: e432.

131. Wang G, Zhan Y, Wang H, Li W. ABT-263 sensitizes TRAIL-resistant hepatocarcinoma cells by downregulating the Bcl-2 family of anti-apoptotic protein. Cancer Chemother Pharmacol 2012; 69: 799-805.

132. Zhang J, Yang PL, Gray NS. Targeting cancer with small molecule kinase inhibitors. Nat Rev Cancer 2009; 9: 28-39.

133. Wang S, Fischer PM. Cyclin-dependent kinase 9: a key transcriptional regulator and potential drug target in oncology, virology and cardiology. Trends Pharmacol Sci 2008; 29: 302-313.

134. Subbiah V, Brown RE, Buryanek J, Trent J, Ashkenazi A, Herbst R et al. Targeting the apoptotic pathway in chondrosarcoma using recombinant human Apo2L/TRAIL (dulanermin), a dual proapoptotic receptor (DR4/DR5) agonist. Mol Cancer Ther 2012; 11: $2541-2546$.

135. Herbst RS, Eckhardt SG, Kurzrock R, Ebbinghaus S, O'Dwyer PJ, Gordon MS et al. Phase I dose-escalation study of recombinant human Apo2L/TRAIL, a dual proapoptotic receptor agonist, in patients with advanced cancer. J Clin Oncol 2010; 28: 2839-2846.

136. Wagner KW, Punnoose EA, Januario T, Lawrence DA, Pitti RM, Lancaster $\mathrm{K}$ et al. Death-receptor O-glycosylation controls tumor-cell sensitivity to the proapoptotic ligand Apo2L/TRAIL. Nat Med 2007; 13: 1070-1077.

137. Passante E, Wurstle ML, Hellwig CT, Leverkus M, Rehm M. Systems analysis of apoptosis protein expression allows the case-specific prediction of cell death responsiveness of melanoma cells. Cell Death Differ 2013; 20: 1521-1531.

138. DuPage M, Jacks $T$. Genetically engineered mouse models of cancer reveal new insights about the antitumor immune response. Curr Opin Immunol 2013; 25: 192-199.

139. Frese KK, Tuveson DA. Maximizing mouse cancer models. Nat Rev Cancer 2007; 7 645-658.

140. Wainberg ZA, Messersmith WA, Peddi PF, Kapp AV, Ashkenazi A, Royer-Joo S et al. A phase $1 \mathrm{~B}$ study of dulanermin in combination with modified FOLFOX6 plus bevacizumab in patients with metastatic colorectal cancer. Clin Colorectal Cancer 2013; 12: 248-254.

141. Kasubhai SM, Bendell JC, Kozloff M, Kapp AM, Ashkenazi A, Royer-Joo S. Phase lb study of dulanermin combined with FOLFIRI (with or without bevacizumab [BV]) in previously treated patients (Pts) with metastatic colorectal cancer (mCRC). J Clin Oncol 2012; 30: abstract 3543.

142. Yee L, Burris HA, Kozloff M, Wainberg Z, Pao M, Skettino S et al. Phase lb study of recombinant human Apo2L/TRAIL plus irinotecan and cetuximab or FOLFIRI in metastatic colorectal cancer (mCRC) patients (pts). Preliminary results. J Clin Oncol 2009; 27: abstract 4129.

143. Soria JC, Smit E, Khayat D, Besse B, Yang X, Hsu CP et al. Phase 1b study of dulanermin (recombinant human Apo2L/TRAIL) in combination with paclitaxel, carboplatin, and bevacizumab in patients with advanced non-squamous non-small-cell lung cancer. J Clin Oncol 2010; 28: 1527-1533

144. Yee L, Fanale M, Dimick K, Calvert S, Robins C, Ing J et al. A phase IB safety and pharmacokinetic (PK) study of recombinant human Apo2L/TRAIL in combination with rituximab in patients with low-grade non-Hodgkin lymphoma. J Clin Oncol 2007; 25: abstract 8078.

145. Tolcher AW, Mita M, Meropol NJ, von Mehren M, Patnaik A, Padavic K et al. Phase I pharmacokinetic and biologic correlative study of mapatumumab, a fully human monoclonal antibody with agonist activity to tumor necrosis factor-related apoptosisinducing ligand receptor-1. J Clin Oncol 2007; 25: 1390-1395.

146. Hotte SJ, Hirte HW, Chen EX, Siu LL, Le LH, Corey A et al. A phase 1 study of mapatumumab (fully human monoclonal antibody to TRAIL-R1) in patients with advanced solid malignancies. Clin Cancer Res 2008; 14: 3450-3455.

147. Mom CH, Verweii J, Oldenhuis CN, Gietema JA, Fox NL, Miceli R et al. Mapatumumab, a fully human agonistic monoclonal antibody that targets TRAIL-R1, in combination with gemcitabine and cisplatin: a phase I study. Clin Cancer Res 2009; 15: 5584-5590.

148. Leong S, Cohen RB, Gustafson DL, Langer CJ, Camidge DR, Padavic K et al. Mapatumumab, an antibody targeting TRAIL-R1, in combination with paclitaxel and carboplatin in patients with advanced solid malignancies: results of a phase I and pharmacokinetic study. J Clin Oncol 2009; 27: 4413-4421.

149. Younes A, Vose JM, Zelenetz AD, Smith MR, Burris HA, Ansell SM et al. A Phase 1b/2 trial of mapatumumab in patients with relapsed/refractory non-Hodgkin's lymphoma. Br J Cancer 2010; 103: 1783-1787.

150. Trarbach T, Moehler M, Heinemann V, Kohne CH, Przyborek M, Schulz C et al. Phase II trial of mapatumumab, a fully human agonistic monoclonal antibody that targets and activates the tumour necrosis factor apoptosis-inducing ligand receptor-1 (TRAIL-R1), in patients with refractory colorectal cancer. $\mathrm{Br} J$ Cancer 2010; 102: 506-512.

151. Greco FA, Bonomi P, Crawford J, Kelly K, Oh Y, Halpern W et al. Phase 2 study of mapatumumab, a fully human agonistic monoclonal antibody which targets and activates the TRAIL receptor-1, in patients with advanced non-small cell lung cancer. Lung Cancer 2008; 61: 82-90.

152. von Pawel J, Harvey JH, Spigel DR, Dediu M, Reck M, Cebotaru CL et al. Phase II trial of mapatumumab, a fully human agonist monoclonal antibody to tumor necrosis factor-related apoptosis-inducing ligand receptor 1 (TRAIL-R1), in combination with paclitaxel and carboplatin in patients with advanced non-small-cell lung cancer. Clin Lung Cancer 2013; 15: 188-196 e2. 
153. Herbst RS, Kurzrock R, Hong DS, Valdivieso M, Hsu CP, Goyal L et al. A first-in-human study of conatumumab in adult patients with advanced solid tumors. Clin Cancer Res 2010; 16: 5883-5891.

154. Doi T, Murakami H, Ohtsu A, Fuse N, Yoshino T, Yamamoto N et al. Phase 1 study of conatumumab, a pro-apoptotic death receptor 5 agonist antibody, in Japanese patients with advanced solid tumors. Cancer Chemother Pharmacol 2011; 68: 733-741.

155. Demetri GD, Le Cesne A, Chawla SP, Brodowicz T, Maki RG, Bach BA et al. First-line treatment of metastatic or locally advanced unresectable soft tissue sarcomas with conatumumab in combination with doxorubicin or doxorubicin alone: a phase $1 / 1 \mathrm{l}$ open-label and double-blind study. Eur J Cancer 2012; 48: 547-563.

156. Chawla SP, Tabernero J, Kindler HL, Chiorean EG, LoRusso P, Hsu M et al. Phase I evaluation of the safety of conatumumab (AMG 655) in combination with AMG 479 in patients (pts) with advanced, refractory solid tumors. J Clin Oncol 2010; 28: abstract 3102.

157. Paz-Ares L, Sánchez Torres JM, Diaz-Padilla I, Links M, Reguart N, Boyer M et al. Safety and efficacy of AMG 655 in combination with paclitaxel and carboplatin (PC) in patients with advanced non-small cell lung cancer (NSCLC). J Clin Oncol 2009; 27: abstract e19048.

158. Saltz L, Infante J, Schwartzberg L, Stephenson J, Rocha-Lima C, Galimi F et al. Safety and efficacy of AMG 655 plus modified FOLFOX6 (mFOLFOX6) and bevacizumab (B) for the first-line treatment of patients (pts) with metastatic colorectal cancer (mCRC). J Clin Oncol 2009; 27: abstract 4079.

159. Kindler HL, Garbo L, Stephenson J, Wiezorek J, Sabin T, Hsu M et al. A phase lb study to evaluate the safety and efficacy of AMG 655 in combination with gemcitabine $(G)$ in patients (pts) with metastatic pancreatic cancer (PC). J Clin Oncol 2009; 27: abstract 4501.

160. Paz-Ares L, Balint B, de Boer RH, van Meerbeeck JP, Wierzbicki R, De Souza P et al. A randomized phase 2 study of paclitaxel and carboplatin with or without conatumumab for first-line treatment of advanced non-small-cell lung cancer. J Thorac Oncol 2013; 8: 329-337.

161. Kindler HL, Richards DA, Garbo LE, Garon EB, Stephenson Jr JJ, Rocha-Lima CM et al. A randomized, placebo-controlled phase 2 study of ganitumab (AMG 479) or conatumumab (AMG 655) in combination with gemcitabine in patients with metastatic pancreatic cancer. Ann Oncol 2012; 23: 2834-2842.

162. Cohn AL, Tabernero J, Maurel J, Nowara E, Sastre J, Chuah BY et al. A randomized, placebo-controlled phase 2 study of ganitumab or conatumumab in combination with FOLFIRI for second-line treatment of mutant KRAS metastatic colorectal cancer. Ann Oncol 2013; 24: 1777-1785.

163. Fuchs CS, Fakih M, Schwartzberg L, Cohn AL, Yee L, Dreisbach L et al. TRAIL receptor agonist conatumumab with modified FOLFOX6 plus bevacizumab for first-line treatment of metastatic colorectal cancer: A randomized phase 1b/2 trial. Cancer 2013; 119: 4290-4298.

164. Plummer R, Attard G, Pacey S, Li L, Razak A, Perrett R et al. Phase 1 and pharmacokinetic study of lexatumumab in patients with advanced cancers. Clin Cancer Res 2007; 13: 6187-6194.
165. Wakelee HA, Patnaik A, Sikic BI, Mita M, Fox NL, Miceli R et al. Phase I and pharmacokinetic study of lexatumumab (HGS-ETR2) given every 2 weeks in patients with advanced solid tumors. Ann Oncol 2010; 21: 376-381.

166. Sikic BI, Wakelee H A, von Mehren M, Lewis N, Calvert AH, Plummer ER et al. A phase lb study to assess the safety of lexatumumab, a human monoclonal antibody that activates TRAIL-R2, in combination with gemcitabine, pemetrexed, doxorubicin or FOLFIRI. J Clin Oncol 2007; 25: 18S 14006.

167. Merchant MS, Geller JI, Baird K, Chou AJ, Galli S, Charles A et al. Phase I trial and pharmacokinetic study of lexatumumab in pediatric patients with solid tumors. $J$ Clin Oncol 2012; 30: 4141-4147.

168. Forero-Torres A, Shah J, Wood T, Posey J, Carlisle R, Copigneaux C et al. Phase I trial of weekly tigatuzumab, an agonistic humanized monoclonal antibody targeting death receptor 5 (DR5). Cancer Biother Radiopharma 2010; 25: 13-19.

169. Forero-Torres A, Infante JR, Waterhouse D, Wong L, Vickers S, Arrowsmith E et al. Phase 2, multicenter, open-label study of tigatuzumab (CS-1008), a humanized monoclonal antibody targeting death receptor 5 , in combination with gemcitabine in chemotherapy-naive patients with unresectable or metastatic pancreatic cancer. Cancer Med 2013; 2: 925-932.

170. Reck M, Krzakowski M, Chmielowska E, Sebastian M, Hadler D, Fox T et al. A randomized, double-blind, placebo-controlled phase 2 study of tigatuzumab (CS-1008) in combination with carboplatin/paclitaxel in patients with chemotherapy-naive metastatic/ unresectable non-small cell lung cancer. Lung Cancer 2013; 82: 441-448.

171. Rocha Lima CM, Bayraktar S, Flores AM, MacIntyre J, Montero A, Baranda JC et al. Phase lb study of drozitumab combined with first-line mFOLFOX6 plus bevacizumab in patients with metastatic colorectal cancer. Cancer Invest 2012; 30: 727-731.

172. Camidge DR, Herbst RS, Gordon MS, Eckhardt SG, Kurzrock R, Durbin B et al. A phase I safety and pharmacokinetic study of the death receptor 5 agonistic antibody PRO95780 in patients with advanced malignancies. Clin Cancer Res 2010; 16: 1256-1263.

173. Sharma S, de Vries EG, Infante JR, Oldenhuis CN, Gietema JA, Yang L et al. Safety, pharmacokinetics, and pharmacodynamics of the DR5 antibody LBY135 alone and in combination with capecitabine in patients with advanced solid tumors. Invest New Drugs 2013; 32: 135-144

(c) This work is licensed under a Creative Commons Attribution 3.0 Unported License. The images or other third party material in this article are included in the article's Creative Commons license, unless indicated otherwise in the credit line; if the material is not included under the Creative Commons license, users will need to obtain permission from the license holder to reproduce the material. To view a copy of this license, visit http://creativecommons. org/licenses/by/3.0/ 